\title{
Maturation of the human B-cell receptor repertoire with age
}

Marie Ghraichy ${ }^{1,2}$, Jacob D. Galson ${ }^{2}$, Aleksandr Kovaltsuk ${ }^{3}$, Valentin von Niederhäusern ${ }^{1,2}$, Jana Pachlopnik Schmid ${ }^{1,2}$, Mike Recher ${ }^{4}$, Annaïse J Jauch ${ }^{4}$, Enkelejda Miho ${ }^{5}$, Dominic F. Kelly ${ }^{6}$, Charlotte M. Deane ${ }^{3}$, Johannes Trück ${ }^{1,2^{*}}$

${ }^{1}$ Division of Immunology, University Children's Hospital, University of Zurich, Zurich, Switzerland ${ }^{2}$ Children's Research Center, University of Zurich, Zurich, Switzerland

${ }^{3}$ Department of Statistics, University of Oxford, Oxford, United Kingdom

${ }^{4}$ Immunodeficiency Laboratory, Department of Biomedicine, University and University Hospital of Basel, Basel, Switzerland

${ }^{5}$ University of Applied Sciences and Arts Northwestern Switzerland FHNW, Institute of Medical Engineering and Medical Informatics, Muttenz, Switzerland

${ }^{6}$ Oxford Vaccine Group, Department of Paediatrics, University of Oxford, Oxford, United Kingdom

*Corresponding author \& lead contact: Johannes Trück, MD DPhil, University Children's Hospital, Steinwiesstrasse 75, 8032 Zurich, Switzerland. +41 44266 7111; johannes.trueck@kispi.uzh.ch

\section{Keywords}

Antibody; B cells; B-cell receptor; Children; Maturation; Repertoire

\section{Content}

- Figures: 8

- Tables: -

- Supplementary Figures: 8

- Supplementary Tables: 2

- Word count manuscript: 4734

- References: 59

\section{Funding}

Swiss National Science Foundation (Ambizione-SCORE: PZOOP3_161147; PZO0P3_183777) (JT) Gottfried und Julia Bangerter-Rhyner-Stiftung (JT)

Olga Mayenfisch Stiftung (JT)

Palatin-Stiftung (JT)

Investment fund of the University of Zurich (JT)

Swiss National Science Foundation (Professorship: PP00P3_181038) (MR)

\section{Author contributions}

JT designed and supervised the study, oversaw analyses, had full access to all the data in the study and takes responsibility for the integrity of the data and the accuracy of the data analysis. The first draft was written by JT and MG. VvN, JDG and MG processed samples and prepared sequencing libraries. MG, JDG, AK and JT performed bioinformatic analysis, revised the manuscript and approved the final version. JPS, MR, AJJ, EM, DFK and CMD contributed to manuscript revision, and approved the final version.

\section{Competing interests}

None of the authors have declared any conflict of interest related to this work. 


\section{Abstract}

B cells play a central role in adaptive immune processes, mainly through the production of antibodies. The maturation of the B-cell system with age is poorly studied. We extensively investigated age-related alterations of naïve and antigen-experienced B-cell receptor (BCR) repertoires. The most significant changes were observed in the first 10 years of life, and were characterized by altered immunoglobulin gene usage and an increased frequency of mutated antibodies structurally diverging from their germline precursors. Older age was associated with an increased usage of downstream constant region genes and fewer antibodies with self-reactive properties. As mutations accumulated with age, the frequency of germline-encoded self-reactive antibodies decreased, indicating a possible beneficial role of self-reactive B-cells in the developing immune system. Our results suggest a continuous process of change through childhood across a broad range of parameters characterizing BCR repertoires and stress the importance of using wellselected, age-appropriate controls in BCR studies.

(149 words) 


\section{Introduction}

B cells play a central role in physiological adaptive immune processes and exert their main effector function through production of antibodies (1). B cells also contribute to the pathogenesis of autoimmune disease via generation of auto-reactive antibodies and modulation of T-cell responses $(2,3)$. The heavy and light chains of the B-cell receptor (BCR, membrane-bound antibody) are generated in the bone marrow by recombining individual variable $(V)$, diversity $(D)$ and joining $(\mathrm{J})$ gene segments through a process called VDJ recombination. Upon antigen recognition, a BCR is further diversified through rounds of somatic hypermutation (SHM) leading to affinity maturation whereby $\mathrm{B}$ cells with improved antigen-binding properties are selected in the germinal center. Class switch recombination (CSR) is also initiated following antigen encounter, causing a change in the constant region of the BCR and in its effector function.

Detailed characterization of $B$ cells and their respective BCR sequences offers important information on B-cell generation and selection as well as immune competence in health and disease. High-throughput sequencing of antibody genes (Ig-seq) has become a widely used tool in human translational research $(4,5)$. Abnormal B-cell responses can be explored by investigating $\mathrm{BCR}$ repertoires from patients and comparing their characteristics to those of healthy controls. The limited data already available suggest that significant changes occur in the properties of BCR repertoires with age (6). It is therefore important to establish robust data on normal BCR repertoires within sufficiently narrow age-bands to fully understand the process of BCR maturation. This will facilitate the use of Ig-seq to understand changes of relevance to childhood disease. Given the high burden of infectious diseases in childhood and the importance of effective immune response to vaccines to prevent infection, this is an important group from which to have normative data. There are very few studies that have used Ig-seq to investigate the healthy BCR repertoire, and these studies include a limited age range of participants (7-10). In a more detailed study, ljspeert et al. reported on the antigen-experienced (i.e. IgA and lgG) BCR repertoires of 38 healthy control $(\mathrm{HC})$ samples with their ages ranging from newborn to 74 years (11). The authors found several characteristics of the studied BCR repertoire varying with age and identified patterns that are specific for isotype subclasses. However, their study was limited by the number of samples from children, the low depth of sequencing, and the small number of B-cell subsets analyzed.

We aimed to assess in detail the naïve and antigen-experienced BCR repertoires in children and young adults using isotype-resolved barcoded RNA-based Ig-seq technology and extensive bioinformatic analysis. This approach allowed us to comprehensively address the age effect on the BCR repertoire in healthy individuals and also provides a robust data set that can serve as a future reference for studying BCR repertoires in children as well as young adults with disease. 


\section{Methods}

\section{Study participants and cell isolation}

Study participants were recruited with informed consent under ethical approval (KEK-ZH 20150555 and EKNZ 2015-187). Blood samples (5-9 mL) were collected at a single time point from 53 healthy participants aged 6 months to 50 years (Supplementary table 1). Peripheral blood mononuclear cells (PBMC) were isolated by centrifugation of PBS-diluted blood over Ficoll-Paque Plus (Sigma-Aldrich). Either PBMC or B cells magnetically sorted using the AutoMACS Pro cell separator and CD19+ microbeads (both Miltenyi Biotec), were lysed in RLT buffer (Qiagen), snap frozen on dry ice and then stored at $-80{ }^{\circ} \mathrm{C}$ prior to use. Cells were counted using an optical microscope and an improved Neubauer chamber. The B-cell number was recorded based on actual counts or estimated using PBMC counts and either B-cell frequencies from flow cytometry performed on the same blood sample or the median percentage of age-dependent reference values (12) if the former was not available.

\section{RNA isolation and library preparation}

RNA was extracted from stored samples using the RNeasy Mini Kit (Qiagen). Reverse transcription was performed using SuperScript III/IV (Invitrogen) according to the manufacturer's instructions and constant region primers that included 14 nt unique molecular identifiers (UMI), and partial p7 adaptors. Two reverse transcription reactions were carried out for each sample: one with a mix of $\lg \mathrm{M}$ and $\lg \mathrm{D}$-specific reverse primers and another with a mix of $\lg \mathrm{A}$, $\lg \mathrm{G}$, and $\lg \mathrm{E}$-specific reverse primers. From 6 samples, one mix with all $C$ region primers were used in a single reaction. Primer sequences with concentrations are included in Supplementary table 2. BCR heavy chain rearrangements were amplified in a two-round multiplex PCR; the first round using a mix of $\mathrm{V}$ family specific forward primers with partial p5 adaptors, and the second round to complete the adaptor sequences. PCR conditions for the first round were $95^{\circ} \mathrm{C}$ for $5 \mathrm{~min}$, either 8 cycles $(\operatorname{lgD} / \operatorname{lgM})$ or 12 cycles (IgA/E/G) of $98{ }^{\circ} \mathrm{C}$ for $20 \mathrm{~s}, 60{ }^{\circ} \mathrm{C}$ for $45 \mathrm{~s}$ and $72{ }^{\circ} \mathrm{C}$ for $1 \mathrm{~min}$, and $72{ }^{\circ} \mathrm{C}$ for 5 minutes. The PCR conditions for the second round were $95^{\circ} \mathrm{C}$ for $5 \mathrm{~min}, 22$ cycles of $98{ }^{\circ} \mathrm{C}$ for $20 \mathrm{~s}, 69{ }^{\circ} \mathrm{C}$ for $20 \mathrm{~s}$ and $72{ }^{\circ} \mathrm{C}$ for $15 \mathrm{sec}$, and $72^{\circ} \mathrm{C}$ for 5 minutes. PCR amplicons were gel-extracted, purified and quantified using the Illumina qPCR library quantification protocol. Individual libraries were normalized based on concentration and then multiplexed in batches of 24 for sequencing on the Illumina MiSeq platform ( 2 × 300 bp paired-end chemistry). Compared with short-read sequencing protocols, long read RNA sequencing on the Illumina MiSeq instrument results in less deep sequencing. However, long read sequencing provides information on the entire VDJ sequence and the constant region of the BCR allowing for accurate distinction between isotypes and subclasses.

\section{Sequence processing, annotation and somatic hypermutation}

Samples were demultiplexed via their Illumina indices, and initially processed using the Immcantation toolkit $(13,14)$. Briefly, raw fastq files were filtered based on a quality score threshold of 20. Paired reads were joined if they had a minimum length of $10 \mathrm{nt}$, maximum error rate of 0.3 and a significance threshold of 0.0001 . Reads with identical UMI (i.e. originating from the same mRNA molecule) were collapsed to a consensus sequence. Reads with identical full-length sequence and identical constant primer but differing UMI were further collapsed resulting in a dataset containing a set of unique sequences per sample and isotype. Sequences were then submitted to IgBlast (15) for VDJ assignment and sequence annotation, and unproductive sequences removed. Constant region sequences were mapped to germline using Stampy (16) for isotype (subclass) annotation, and only sequences with a defined constant region were kept for further analysis. The number and type of $\mathrm{V}$ gene mutations was calculated using the shazam $\mathrm{R}$ package (14). Levels of somatic hypermutation (SHM) were determined by calculating $\mathrm{V}$ gene mutations in individual sequences, and mean values were calculated across samples and cell subsets. 
bioRxiv preprint doi: https://doi org/10.1101/609651; this version posted December 20, 2019. The copyright holder for this preprint (which was not certified by peer review) is the author/funder, who has granted bioRxiv a license to display the preprint in perpetuity. It is made available under aCC-BY-NC-ND 4.0 International license.

\section{Sequence clustering, clonal lineages and antigen-driven selection}

Sequences were independently clustered for each sample to group together those arising from clonally related $\mathrm{B}$ cells. The clustering required identical $\mathrm{V}$ and $\mathrm{J}$ segment use, identical complementary-determining region (CDR) 3 length, and allowing a 1 in 15 nucleotides mismatch in the CDR3 as previously determined (7). Lineages were constructed from clusters using the alakazam $\mathrm{R}$ package (17). To account for read depth variation, lineage trees were constructed on subsamples of the original data. Specifically, we randomly sampled 25'609 sequences (corresponding to the lowest number of reads available for a sample) from every $\mathrm{HC}$ sample. For calculation of selection pressure of samples, individual sequences within clusters are not independent events, so an effective representative sequence of each clonal group was determined using the default settings of shazam. Selection pressure was calculated using BASELINe (18) implemented within shazam. The statistical framework used to test for selection was CDR_R / (CDR_R + CDR_S), which normalizes for the observed increase in the total number of mutations with age. The replacement/silent (R/S) mutation ratio was measured separately in framework regions (FWRs) and CDRs. In sequences with replacement but no silent mutations, the number of silent mutations was set to 1 .

\section{From Sequence to Structure}

The SAAB+ pipeline was employed to annotate BCR repertoires with structural information (19). Briefly, BCR repertoires were numbered with the IMGT scheme (20) and filtered for structural viability using 'ANARCI parsing' (21) as per the first steps of the ABOSS algorithm (22). Sequences were filtered out that (i) could not be aligned to the human Hidden Markov Model (HMM) profile of an IMGT germline (ii) had a J gene sequence identity of less than $50 \%$ to a human IMGT germline or (iii) contained non-amino acid entries in CDRs. Since the primer masking step in pRESTO (13) can remove the first framework region and positions 127 and 128 of some sequences, ANARCI parsing was customized to account for these exceptions. To retain as many sequences as possible for structural annotation, we substituted undetermined residues in the framework region with the residues from their respective parent germline genes.

To annotate the numbered sequences with canonical loop class information, SAAB+ employs SCALOP (23) with the IMGT CDR definition (20). The expected coverage of canonical loop class sequences with SCALOP is $93 \%$, where $89 \%$ of predicted templates will have root-mean-square deviation (RMSD) values for the backbone atoms within $1.5 \AA$ of the correct structure. The SCALOP database dated July 2018 was used in this study.

SAAB+ employs FREAD (24) to annotate CDR-H3 loops with the Protein Data Bank (PDB) code (25) of the closest crystallographically-solved CDR-H3 structure (template). Only CDR-H3 sequences with loop lengths between 5 and 16 were investigated. The expected average RMSD of CDR-H3 template prediction for the human BCR repertoire data is $2.8 \AA$, with an expected coverage of $48 \%$ (19). PDB templates within a $0.6 \AA$ RMSD radius were clustered together (19), reducing 2'943 PDB templates to 1'169 CDR-H3 PDB clusters.

\section{Statistical analysis and graphing}

Statistical analysis and plotting were performed using $\mathrm{R}(26)$; all plots were produced using the ggplot2 and ggpubr packages $(27,28)$. Heatmaps were visualized using the ComplexHeatmap $R$ package (29). PCA plots were created using the R package factoextra (30). In cases where a model was fitted to the data, the $R$ squared of the model and the $p$ value of the chi-squared goodness-of-fit test are shown in the bottom right of the graphs. Other specific tests used are detailed in the figure legends.

\section{Classification of sequences into cell subsets using isotype and number of mutations}

Using constant region annotation and mutation number, individual sequences were grouped into biologically different subsets based on known B-cell subpopulations. Based on the frequency distribution of mutations for $\lg D$ and $\lg M$ sequences, those with up to 2 nt mutations across the 
entire V gene were considered "unmutated" (naïve) to account for allelic variance (31) and remaining PCR and sequencing bias (Supplementary figure 1). All class-switched sequences were defined as antigen-experienced irrespective of their $V$ gene mutation count. Because of very low sequence numbers, IgE and IgG4 transcripts were excluded from most analysis. The number of sequences of the different subsets among total transcripts by individual are found in Supplementary table 1.

\section{Data availability}

Raw sequence data used for analysis in this study are available at the NCBI Sequencing Read Archive (www.ncbi.nlm.nih.gov/sra) under BioProject number PRJNA527941 including metadata meeting MiAIRR standards (32). The processed and annotated final dataset is available in Zenodo (https://doi.org/10.5281/zenodo.3585046) along with the protocol describing the exact processing steps with the software tools and version numbers. 


\section{Results}

We obtained 78'702'939 raw sequences from samples of 53 healthy study participants. Processing, filtering and collapsing resulted in a final dataset of 8'341'669 unique BCR sequences used for downstream analysis. The numbers of unique sequences were significantly reduced after UMI-based collapsing resulting in a correlation with the B-cell numbers per sample (Supplementary figure 2).

\section{$\mathrm{V}$ family and $\mathbf{J}$ gene usages change with age}

Although previous work has observed common patterns of gene segment usage and has suggested a strong dependence on an individual's germline genetic background $(33,34)$, the relative contributions to variance from age remained unclear. Proportions of sequences assigned to the different $\mathrm{V}$ gene families and $\mathrm{J}$ genes were calculated for each sample and B-cell subset. The overall distribution of $\mathrm{V}$ family and $\mathrm{J}$ gene usage were different in older individuals compared with younger age groups. In particular, frequencies of V1 family sequences significantly decreased with age in naïve and mutated $\lg D$ and $\lg M$ sequences. This decrease was also observed in $\lg G$ and IgA antibody although with higher individual variation in older age groups (Figure 1A). No clear pattern was found in the usage of the other $V$ families by age (Supplementary figure 3A). Such changes in $\mathrm{V} 1$ family genes were due to age-related alterations in several $\mathrm{V}$ genes, particularly VH1-8 (Supplementary figure 5).

There were also changes in the overall $\mathrm{J}$ gene usage over the first 10 years of life marked by a significant decrease in the frequencies of sequences assigned to J6 in IgG antibody (Figure 1B). Frequencies of the other $\mathrm{J}$ genes by age group are shown in Supplementary figure 3B. In line with previous work $(35,36)$, we find that BCR sequences with rearranged J6 gene have longer junctions (Supplementary figure $3 \mathrm{C}$ ). Along with a declining J6 usage with age, a significant decrease in junction length was observed in IgG subsets of older individuals (Figure 1C). However, even within IgG J6 antibody, junction length significantly decreased with age indicating that shorter junctions in older individuals are not solely the result of altered $\mathrm{J}$ gene usage (Supplementary figure 4).

\section{Somatic hypermutation exponentially increases in the first 10 years of life}

There was a significant increase in SHM in all antigen-experienced subsets with age, which was most prominent in the first 10 years of life (Figure 2A). Substantial changes in mutation counts were found in all IgA and IgG subsets with exponential increases in children under 10 years and more linear progression between 10 and 50 years. IgM memory showed the smallest change of all subsets with some increase in children and a plateau from the $2^{\text {nd }}$ decade while there was no agedependent change for IgD memory antibody. However, the proportion of mutated IgM antibody per sample increased from 0.1 in 0-3 year olds to an average of 0.4 in older individuals (Figure 2B). An age-related increase in the proportion of mutated sequences was also seen for $\lg A$ and $\lg G$ although at a higher level (Figure 2B). 
bioRxiv preprint doi: https://doi.org/10.1101/609651; this version posted December 20, 2019. The copyright holder for this preprint (which was not certified by peer review) is the author/funder, who has granted bioRxiv a license to display the preprint in perpetuity. It is made available under aCC-BY-NC-ND 4.0 International license.
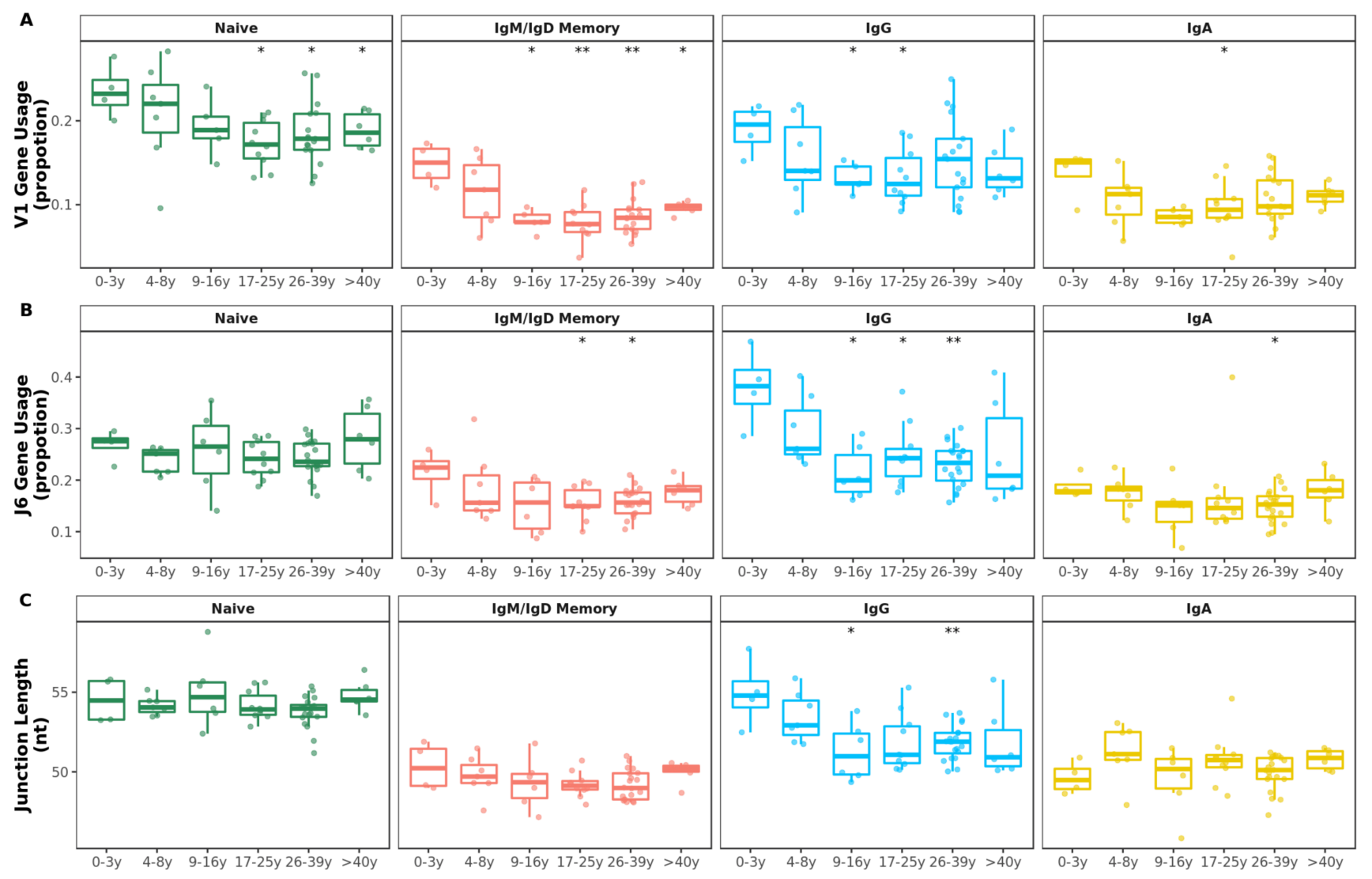

Figure 1: $\mathrm{V}$ family and $\mathrm{J}$ gene usage changes in early childhood. $A \mathrm{~V} 1$ family usage was significantly reduced in older compared with younger individuals in all BCR repertoires. $B \mathrm{~J} 6$ gene usage significantly decreased during the first 10 years of life mostly in IgG subsets. $C$ Mean junction length significantly decreased in the first 10 years of life exclusively in IgG subsets. Comparison of each age group to the 0-3y group was performed using the Wilcoxon test. ${ }^{*} p<0.05,{ }^{* *} p<0.01$

\section{Sequences with predicted antibody structures diverging from germline increase with age}

Crystallographic studies have shown that antibody CDR-H1 and CDR-H2 loops can adopt a very limited number of structural conformations, known as canonical loop classes $(37,38)$. These canonical classes are considered to be separate and distinct structures of the CDRs and can be rapidly and accurately annotated by SCALOP (23). The proportion of sequences in which either $\mathrm{CDR}-\mathrm{H} 1$ and $\mathrm{CDR}-\mathrm{H} 2$ had switched from the canonical class of their germline increased with age for most antigen-experienced subsets, similar to the increasing mutation number with age (Figure 2C).

Structures of CDR3 were predicted by mapping sequences to antibody structures in the PDB and annotated with a PDB code identifier. The proportion of every PDB cluster within individual and repertoire was calculated and normalized to zero mean and unit variance across individuals. PDB cluster usages were similar across individuals and age with a small number of positive outliers (frequent usage) that were private to each individual (Supplementary figure 6). 
bioRxiv preprint doi: https://doi.org/10.1101/609651; this version posted December 20,2019 . The copyright holder for this preprint (which was not certified by peer review) is the author/funder, who has granted bioRxiv a license to display the preprint in perpetuity. It is made available under aCC-BY-NC-ND 4.0 International license.

A
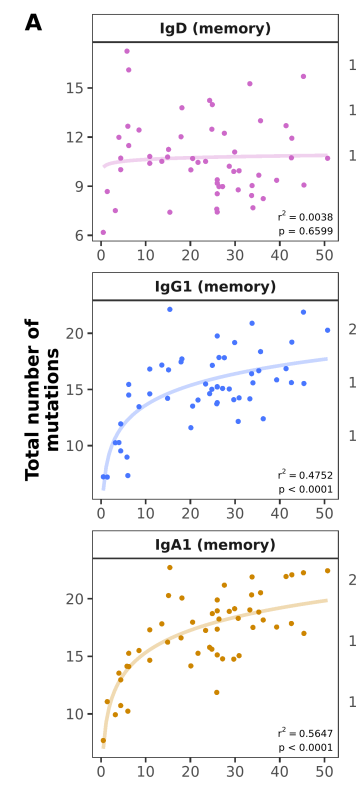

B

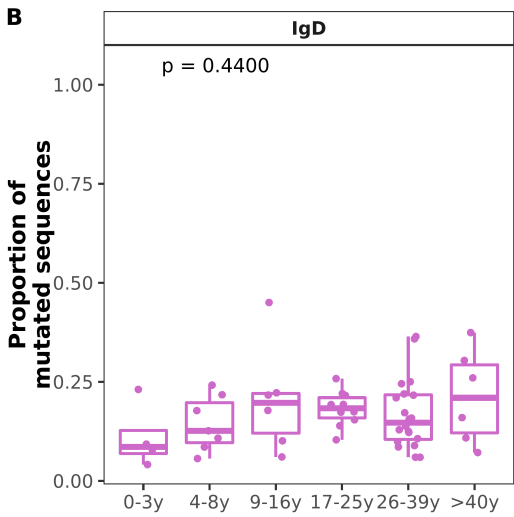

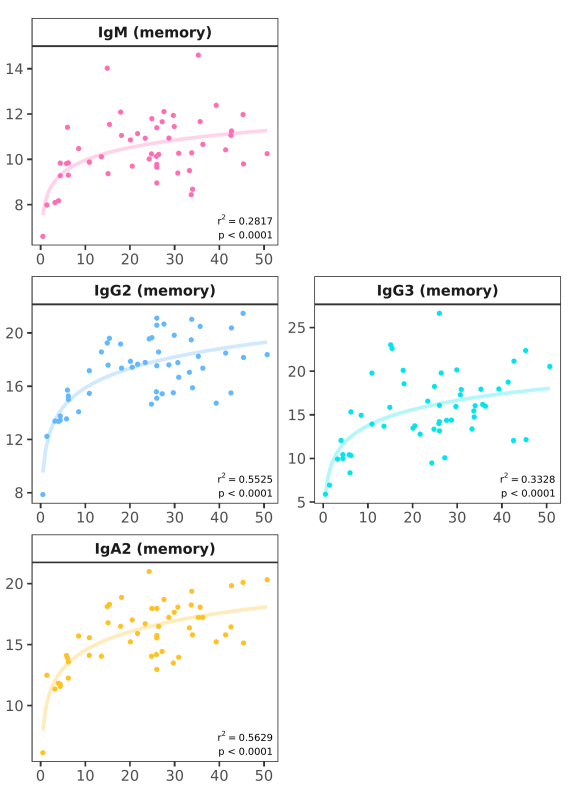

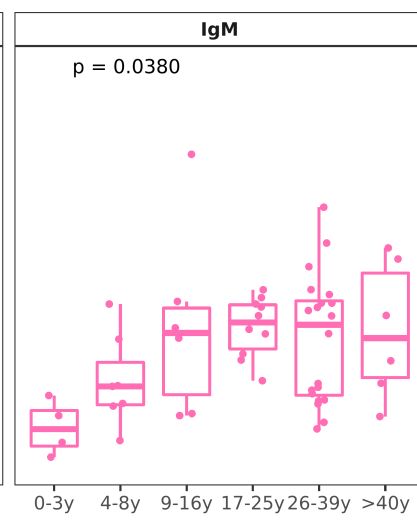

C

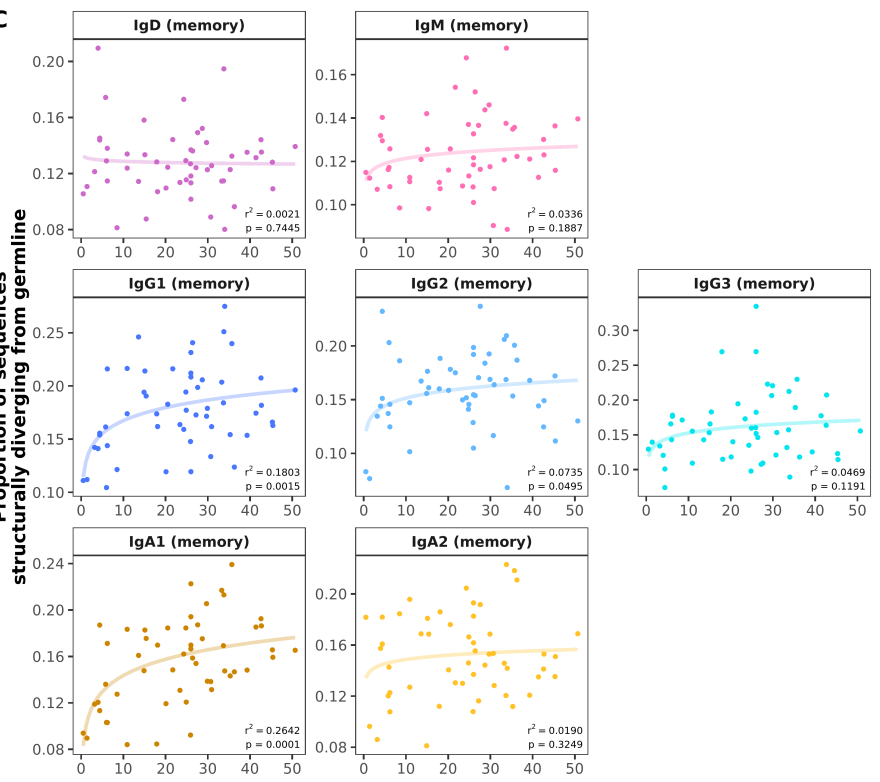

Figure 2: Age-related changes in somatic hypermutation and predicted antibody structure. $A$ Mean number of $\checkmark$ gene mutations by individual and B-cell subset with fitted logarithmic curves. Somatic hypermutation increased mainly in the first 10 years of life with some differences between cell subsets. $B$ The proportion of memory $\operatorname{lgD}$ and memory $\operatorname{lgM}$ out of all $\mathrm{IgD} / \mathrm{lgM}$ antibody and the proportion of mutated $\mathrm{IgG}$ and $\lg A$ antibody within repertoires showed significant increases in the first 10 years of life. $C$ The proportion of sequences structurally different from germline increased in early childhood in all B-cell subsets. Statistical differences between groups were tested using the KruskalWallis test.

\section{Structural but not sequence clusters are commonly shared between individuals}

For each of the 53 individuals in this study, we calculated the frequency of sequence clusters (i.e. clonally related sequences) that are unique to the individual, the frequency of clusters that are shared with two, three or more subjects. Overlap with $\mathrm{n}$ subjects was quantified as the number of clusters shared with only $\mathrm{n}$ individuals divided by the total number of clusters in an individual's repertoire. We found that on average, $84.1 \%$ of clusters were unique to the individual, while $2.5 \%$, $0.2 \%, 0.04 \%$ and $0.02 \%$ of clusters were shared with $2,10,25$ and 45 or more other individuals, respectively (Figure 3A). Sharing of structural clusters, however, was much more frequent with the majority of clusters (57\%) shared by all 53 individuals and on average only $0.03 \%$ of clusters unique to the individual (Figure 3B). Neither sequence nor structural cluster sharing showed agerelated changes. 
bioRxiv preprint doi: https://doi.org/10.1101/609651; this version posted December 20,2019 . The copyright holder for this preprint (which was not certified by peer review) is the author/funder, who has granted bioRxiv a license to display the preprint in perpetuity. It is made

$\mathbf{A}$

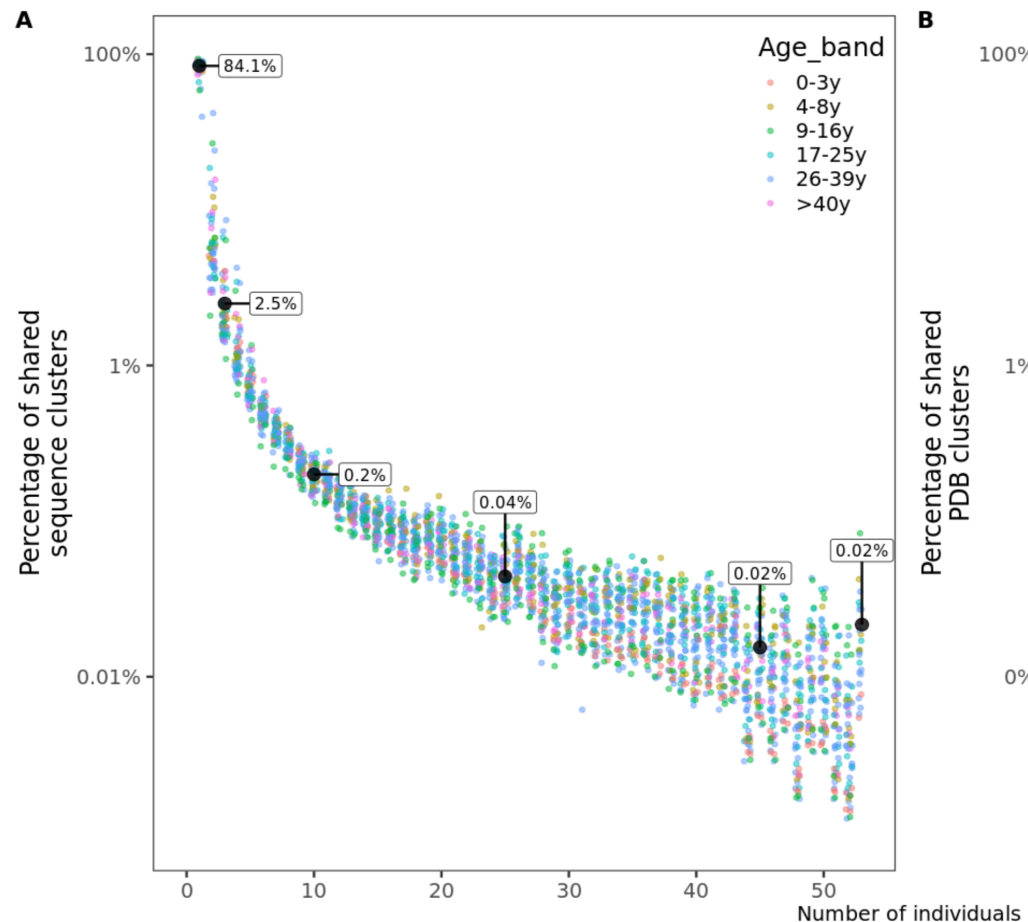
available under aCC-BY-NC-ND 4.0 International license.

Figure 3: Sharing of sequence and structural clusters among the $\mathbf{5 3}$ healthy participants of different ages. $A$ Percentage of sequence clusters shared by $\mathrm{n}$ individuals. $B$ Percentage of structural clusters shared by $\mathrm{n}$ individuals. For structural clusters, zeros were replaced by $0.01 \%$ to be displayed on a logarithmic scale but labeled as $0 \%$.

\section{Older individuals display more mature clonal lineages and antibody with antigen-driven} selection

Lineage trees were constructed from clusters of clonally related sequences and used to determine the evolutionary relationship within clusters (Figure 4A). The mean trunk length, representing the distance between the most recent common ancestor and germline sequence as a measure of the maturity of a lineage (39), greatly increased with age (Figure 4B). There was no relationship between age and the Gini index, which predicts whether lineages are dominated by a single clone (high index) or has a broad branching structure (low index) (Figure 4C). To account for differences in read depth, these characteristics were calculated on subsampled data so that the numbers of sequences were similar between individuals.

A

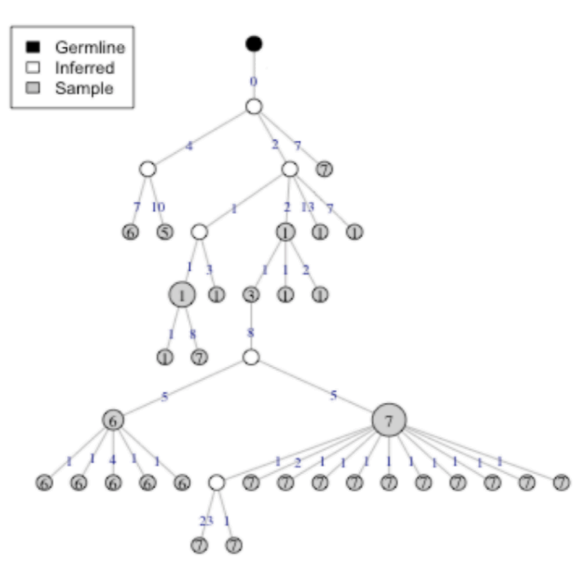

B

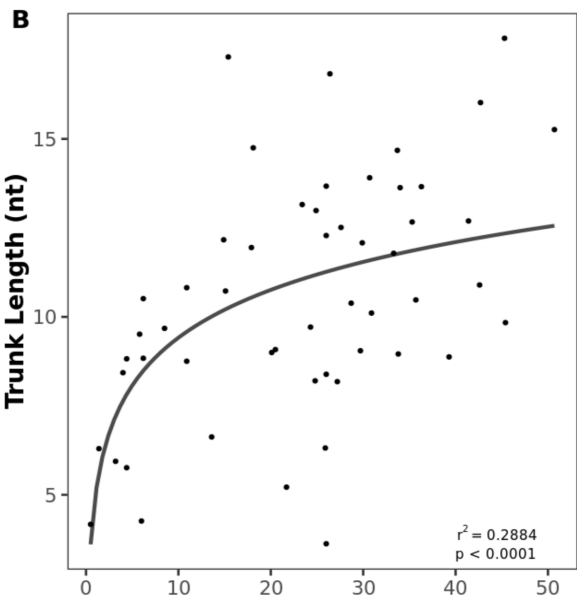

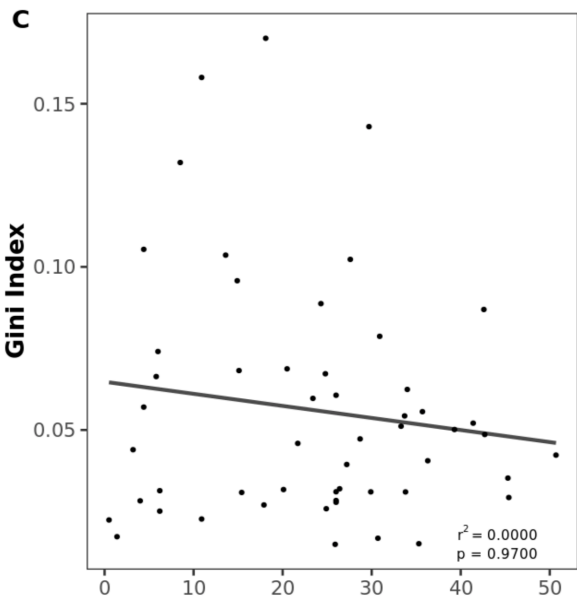

Age (Years)

Figure 4: Age-related changes in clonal expansions. $A$ Example lineage tree with each node representing a sequence and the size of the node indicating the number of identical sequences. The number of mutations between the sequences (nodes) is shown on top of the connecting lines. $B$ Correlation between age and mean trunk length with a fitted logarithmic curve. $C$ Correlation between mean Gini index and age with a fitted linear model. 
Insights into the process of antigen-driven selection can be gained by analyzing the mutational pattern in antigen-experienced repertoires. The R/S ratio in CDRs showed a marked increase in all antigen-experienced subsets between 0 and 10 years of life (Figure 5A). In samples from study participants older than 10 years, the R/S ratio was largely constant with values of around 3-3.5 in all B-cell subsets. In contrast, the R/S ratio was less variable and lower in FWRs compared with CDRs and no association with age was found (Supplementary figure 7). Next, we determined selection pressure using a Bayesian estimation of antigen-driven selection (BASELINe), which calculates selection by comparing the observed mutations to expected mutations derived from an underlying SHM targeting model (18). In CDRs, there was a general trend towards an ageassociated decrease in selection strength for $\lg A$ and $\lg G$ antibody whereas this was constant across age for IgD or IgM sequences (Figure 5B). The statistical framework used to test for selection was CDR_R / (CDR_R + CDR_S), which normalizes for the observed increase in the total number of mutations with age.

A
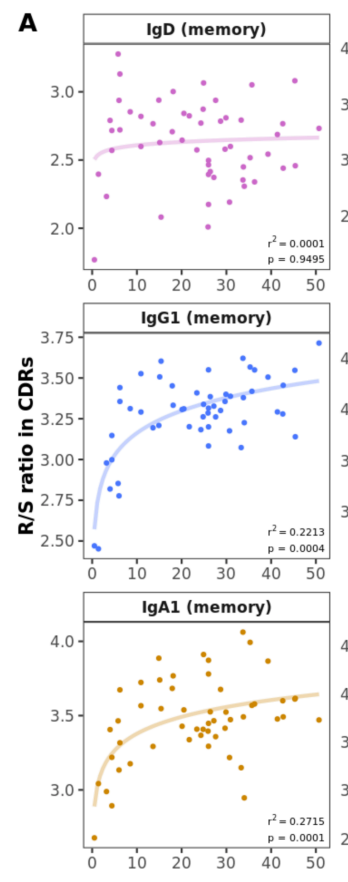
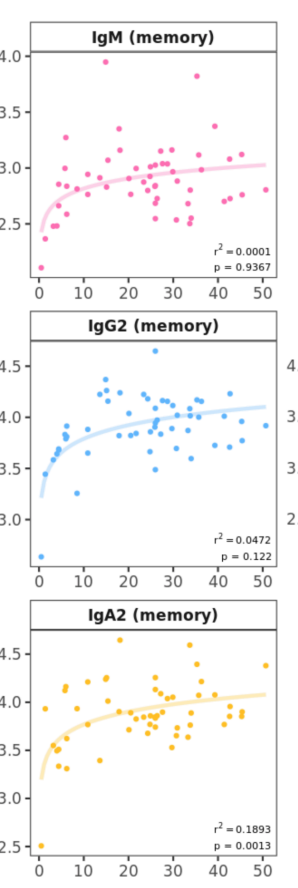
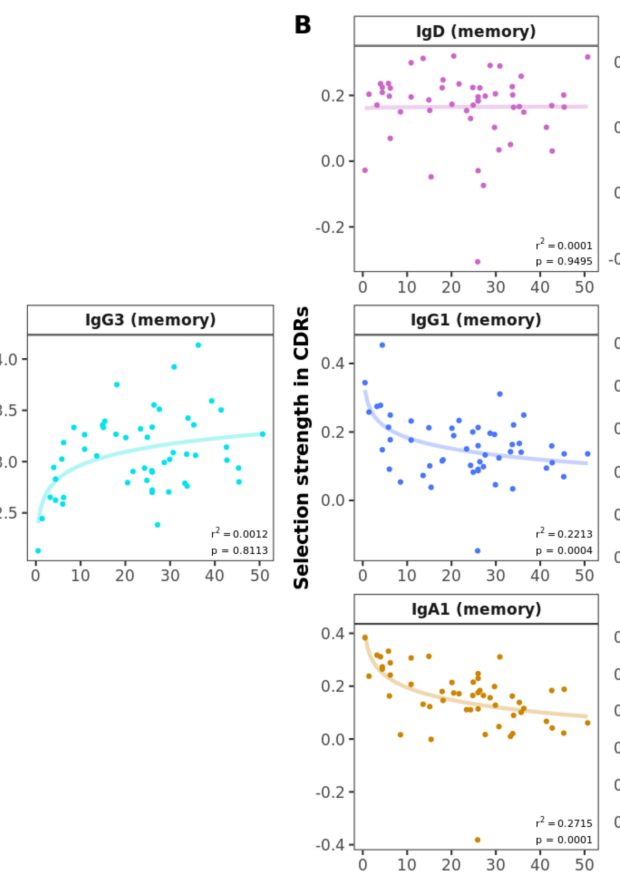

Age (Years)

Figure 5: Age-related changes in antigen-driven selection. A) Mean R/S ratio in $V$ gene CDRs as a measure of selection pressure showed an increase in early childhood in all B-cell subsets. For sequences with replacement but no silent mutations, the number of silent mutations was set to 1. B) Mean selection strength in CDRs calculated using BASELINe decreases with age in class switched subsets. 


\section{Usage of $\lg G 2$ and $\lg A 2$ subclasses increase with age}

Subclass usages were calculated within $\lg A$ and $\lg G$ repertoires to explore age-dependent classswitching patterns. In most age groups, IgG1 sequences were the most commonly detected, followed by IgG2, IgG3, and IgG4 sequences. However, the proportion of IgG2 sequences increased with age ( $p=0.0140$, Kruskal-Wallis by age group) at the expense of lower usage of IgG1 $(p=0.0086$, Kruskal-Wallis) and IgG3 ( $p=0.1900$, Kruskal-Wallis) sequences in older individuals. Similarly, IgA1 was most commonly used in all age groups and there was a non-significant trend towards a higher proportion of IgA2 sequences with age $(p=0.0960$, Kruskal-Wallis) (Figure 6).
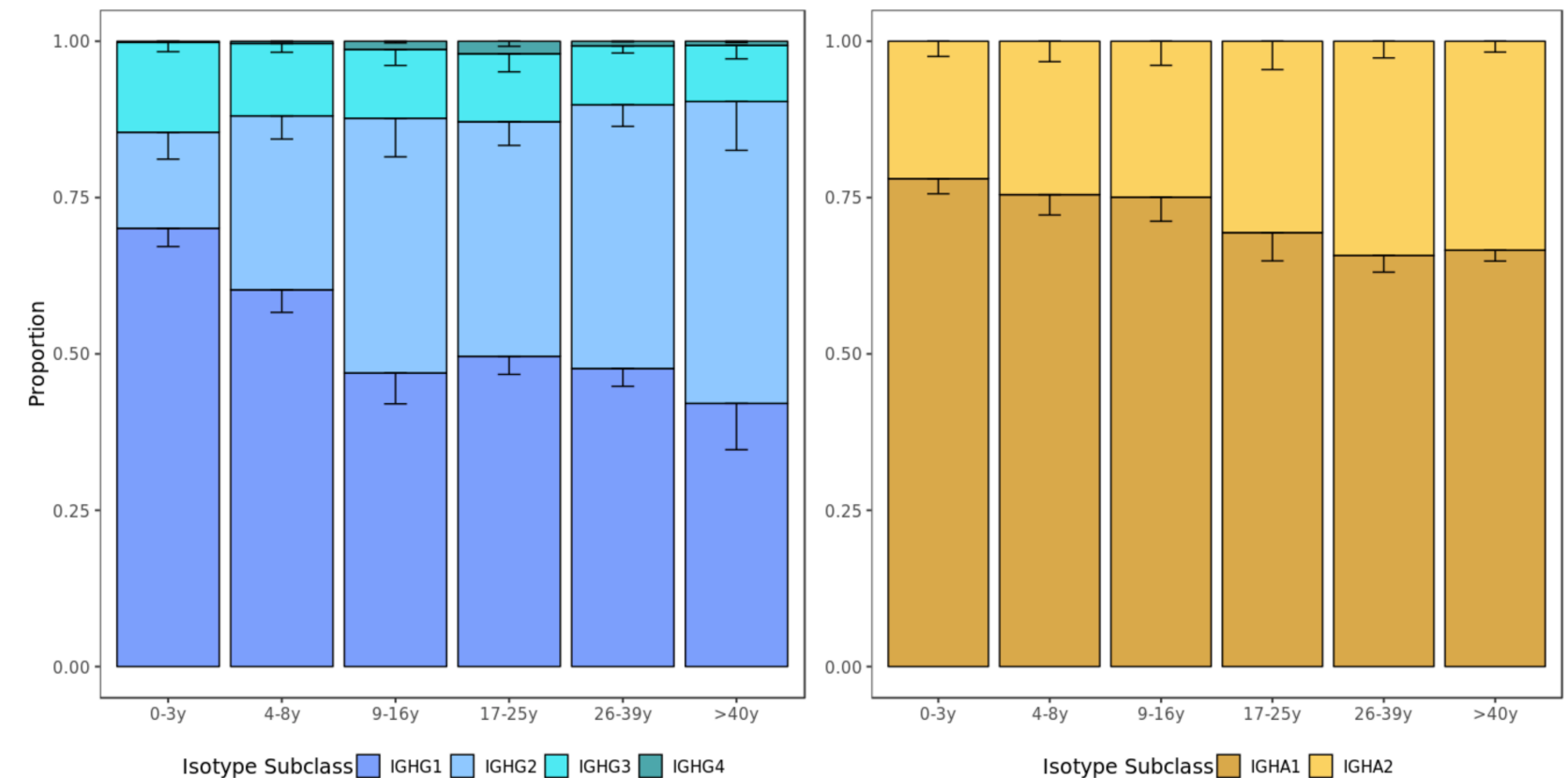

Figure 6: Usage of $\lg G$ and $\lg A$ subclasses by age group. The $\lg G$ and $\lg A$ isotype subclass usage changes with age. Error bars represent standard error of the mean.

\section{Repertoires from older individuals contain more self-tolerant sequences}

Self-reactive antibodies share sequence characteristics that can be explored by lg-seq. These include an increased usage of certain V genes, mainly VH4-34, and usage of longer CDR3 with positively charged or hydrophobic residues (40-42). We investigated how these metrics vary with age in healthy individuals. Apart from the decreasing junction length in IgG subsets (Figure 1C), we found that age has no impact on charge or hydrophobicity of BCR repertoires (Supplementary figure 8). $\mathrm{VH} 4-34$ usage was also unrelated to age whereas a more detailed SHM analysis including self-reactive motifs of $\mathrm{VH} 4-34$ sequences revealed an age-specific pattern. The $\mathrm{VH} 4-34$ germline contains an Ala-Val-Tyr (AVY) hydrophobic patch in FWR1 that is not present in other V segments and is thought to contribute to the self-reactive property of this gene $(43,44)$. Another feature of the VH4-34 germline associated with autoimmunity is the presence of an Asn-X-Ser Nglycosylation sequon (NHS) in CDR2 that modulates antibody avidity (45). Previous research has shown that mutating one or both of these motifs drives specificity of these sequences away from self, thereby contributing to peripheral tolerance. Lower frequencies of both unmutated AVY and $\mathrm{NHS}$ were present in healthy elderly individuals while there was a relative accumulation of single and double-mutated motifs in VH4-34 with age (Figure 7). This pattern was observed across all antigen-experienced subsets but was only statistically significant for $\lg A$ and $\lg G$ antibody $(p=0.0110$ and $p=0.0036$ respectively; $p=0.1800$ for lgM/lgD memory; Kruskal-Wallis test). 

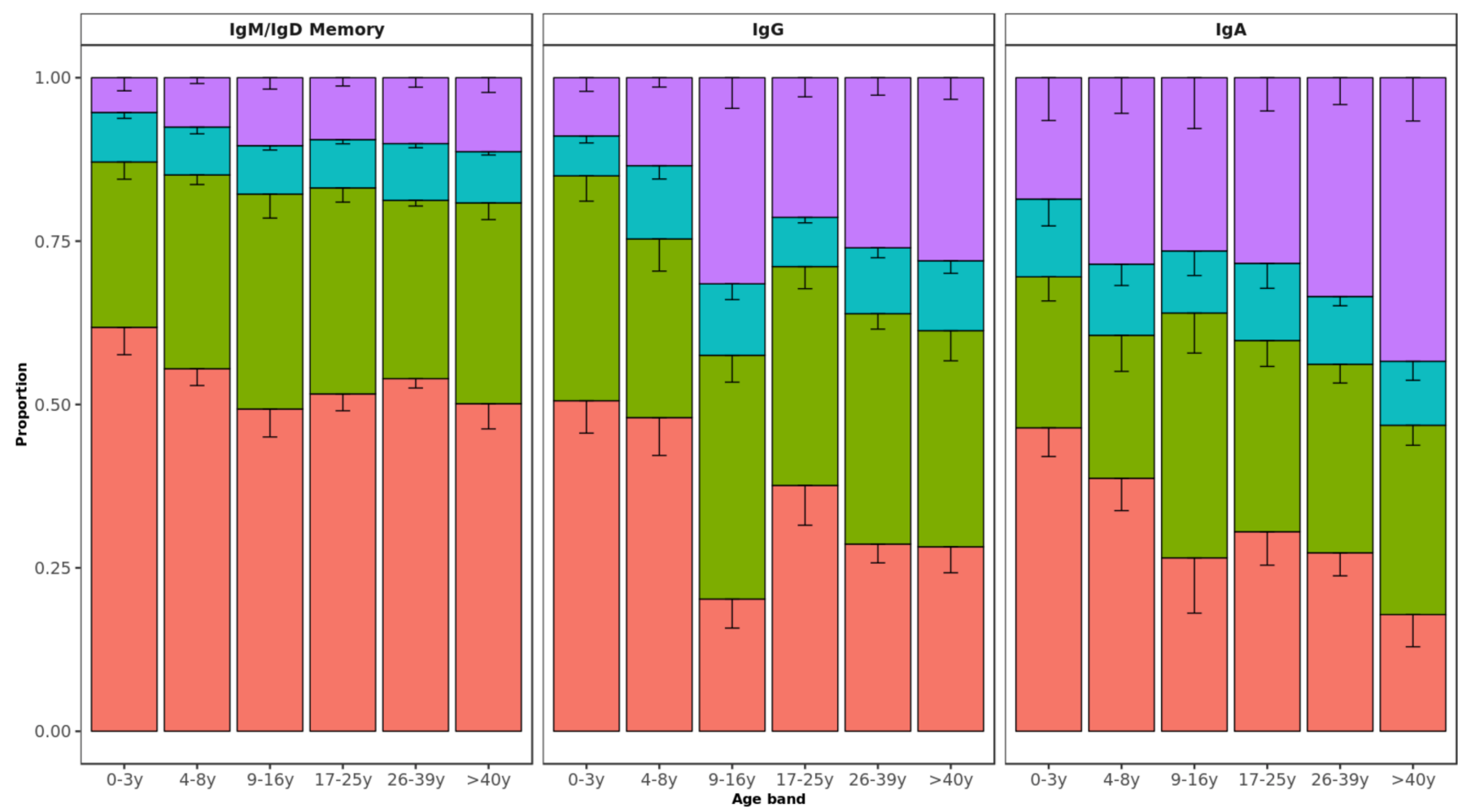

Motifs $\square$ AVYmut_NHSmut $\square$ AVYmut_NHS $\square$ AVY_NHSmut $\square$ AVY_NHS

Figure 7: VH4-34 motifs by age group. Bar plots represent the proportion of sequences with mutated AVY and/or NHS motifs in IgD/lgM, IgG and IgA. Error bars indicate standard error of the mean. Proportion of sequences with both unmutated motifs decreases with age.

\section{Combining age-related repertoire features distinguishes between children and adults}

Principal component analysis (PCA) based on the age-driven variables including mutation, R/S ratio, junction length, gene usage and proportion of sequences structurally divergent from germline clearly showed distinct grouping of children younger than 9 years old and individuals older than 10 years old in antigen experienced repertoires. This distinction was most clearly observed in the class-switched IgG and IgA repertoires. In IgD/IgM mutated sequences, children less than three years old were separate from other individuals whereas the repertoire characteristics in older age categories overlapped. 
bioRxiv preprint doi: https://doi.org/101101/609651; this version posted December 20, 2019. The copyright holder for this preprint (which was not certified by peer review) is the author/funder, who has granted bioRxiv a license to display the preprint in perpetuity. It is made available under aCC-BY-NC-ND 4.0 International license.

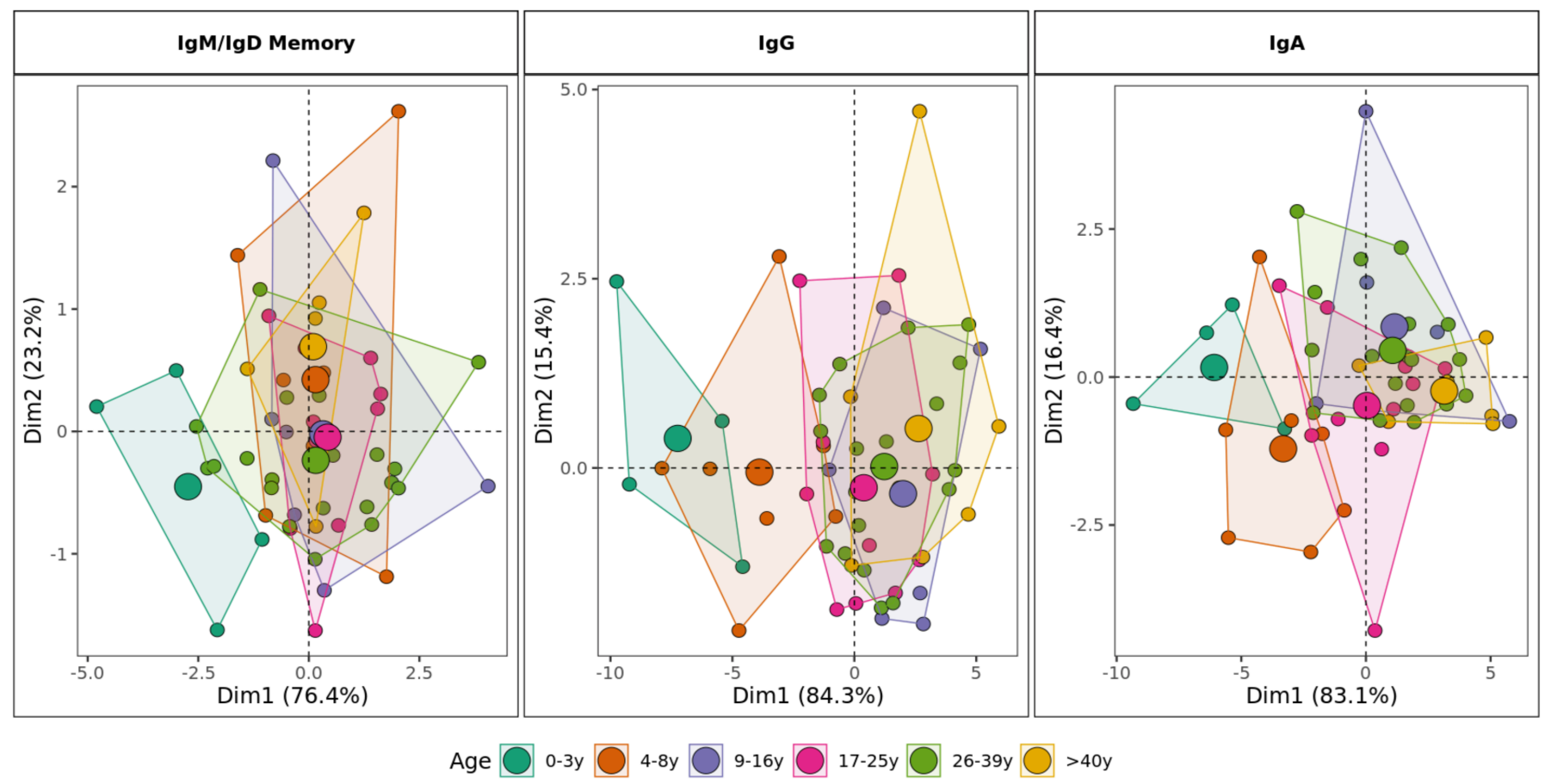

Figure 8 Stratification of BCR repertoires by age group. Principal component analysis by age category including mutation rate, $\mathrm{R} / \mathrm{S}$ ratio, $\mathrm{V} 1$ gene family usage, $\mathrm{J} 6$ gene usage, junction length and proportion of sequences structurally divergent from germline as variables. For class-switched IgG and IgA, the proportion of IgG2 and IgA1 are included respectively. Areas are the convex hulls of the age group and the largest point of one color represents the center of that hull. 


\section{Discussion}

In this study, we found an extensive maturation of B-cell responses in the first 10 years of life consistent with what would be expected with cumulative antigen exposure and a generally more developed and stable B-cell compartment in older individuals. Further antibody repertoire alterations continue to be made thereafter, although at a lower rate. The results presented here constitute the most in-depth evaluation of the BCR repertoire with age. This study also provides a detailed reference data set of isotype and subclass-specific BCR repertoires of healthy individuals across a relevant age range and stresses the importance of using well-selected, age-appropriate controls in future studies.

Previous studies have suggested that immunoglobulin gene usage is strongly genetically determined as it was conserved between monozygotic twins and across multiple time points within a given individual $(7,33)$. We found age-dependent alterations in both $\mathrm{V}$ family and $\mathrm{J}$ gene usage in antigen-experienced repertoires suggesting either polyclonal negative selection of V1- and J6containing $B$ cells or positive selection of non-V1/J6-bearing $B$ cells during maturation of the adaptive immune system. However, here we also saw that $V$ family gene usage changed in naïve repertoires that are supposedly unaffected by antigen exposure and not subject to antigen-driven selection pressure, indicating preferential development and/or survival of V1-bearing B cells in young children. Although the potential benefit and mechanism behind these age-related $\mathrm{V}$ family gene alterations remain unclear, these findings suggest that immunoglobulin gene usage in developing $B$ cells is less conserved than previously thought.

In line with earlier findings $(11,46,47)$, we observed extensive maturation of antigen-experienced repertoires characterized by accumulation of somatically hypermutated B-cell antibody with evidence of strong positive selection in older individuals. The observed decrease in selection pressure in some class-switched subsets indicates that young individuals show accelerated dynamics to achieve highly selected sequences compared with older individuals. Of note, detailed analysis allowed to investigate characteristics of mutated IgM/D antibody separately, which were observed at a higher frequency and with a greater number of mutations in older individuals. These findings indicate that the pool of circulating peripheral blood naïve B cells is continuously diminishing with age, possibly contributing to a decreasing capacity to effectively respond to novel antigens in older individuals (48). We also observed a substantially higher proportion of unmutated $\lg A / G$ antibody in young children compared with adults (49), a finding that has not yet been recognized and is of unknown significance. However, these results are in line with previous in vitro studies (50) demonstrating that class-switch recombination and somatic hypermutation can occur independently and suggest class-switching to be an important element of B-cell responses in young children.

Along with other characteristics indicative of antigen-driven maturation we found that the proportion of sequences with structures differing from germline increased with age, which was most pronounced for $\lg \mathrm{G} 1$ and $\lg \mathrm{A} 1$ subsets. To date, there is limited information on predicted antibody structures derived from high-throughput adaptive immune receptor repertoire sequencing data (51, 52). In line with measures of antigen-driven selection, there was a positive linear relationship between number of mutations and structural alterations of antigen-experienced sequences indicating that alteration of the three-dimensional structure is important to achieve high specificity and affinity of the antibody. By annotating individual sequences with PDB codes, we were able to investigate commonalities of CDR3 structures between individuals. In particular, in contrast to sharing on the sequence level, the majority of PDB clusters were public while only a very small percentage of PDB clusters were private to the individual. Although this comparison is influenced by the much smaller number of potential PDB clusters, the use of common PDB clusters indicates that a large number of different sequences can underlie similar antibody structures. Future work, such as the investigation of PDB usage in patients with immune disorders, will help determine how antibody structures can be used to assess global immune responses. 
We found an increase in the usage of $\lg A 2 / \lg G 2$ antibody with age, similar to what has been seen in a recent study on the isotype subclasses surface expression of peripheral blood B cells (53). While human IgG subclasses have been extensively studied (54), there is limited information on the functional difference between the two IgA subclasses, whose structures mainly differ in the length of the hinge region (55). IgG2 has been implicated in the immune responses to capsular polysaccharides of bacteria such as $S$. pneumoniae that are commonly colonizing the oropharynx of young children and thereby induce polysaccharide-specific serum antibody (56). Our findings also match the sequential model proposed for CSR: with age, and after multiple encounter with the same antigen, class-switched memory B cells re-enter the germinal center to undergo a second round of CSR and switch towards more downstream constant region genes (57).

The majority of early immature human B cells display self-reactivity and although most of these are removed during B-cell development, a substantial proportion of mature B cells may still be directed against autoantigens (40). Antibodies encoded by germline $\mathrm{VH} 4-34$ are intrinsically self-reactive antibodies mediated by a hydrophobic patch and a glycosylation sequon $(43,45)$. Unmutated VH434 antibody are more common in naïve than antigen-experienced repertoires as receptor editing of these antibodies drives specificity away from self $(44,58)$. In contrast to adults, we found that a substantial proportion of VH4-34 IgG and IgA antibody from children are unmutated, with frequencies gradually decreasing with age. Previous work has shown that germline VH4-34expressing IgG B cells recognized antigens from commensal gut bacterial (58) and hence, the higher frequency of these cells in children may be related to ongoing immune responses against gut pathogens in this age group.

This study used Ig-seq technology coupled with bioinformatic methods to study in detail the BCR repertoires of healthy individuals and investigate the effect of age on repertoire characteristics. We chose a cross-sectional study design and - although unlikely - can therefore not exclude that longitudinal assessment of maturation on an individual basis may differ from the presented findings. For practical reasons, the number of input cells was variable between study participants, which resulted in variable sequence numbers per sample. For analysis where sequence number variability was considered to be of major relevance, such as constructing lineage trees, subsampling to an equal number of sequences per individual was performed.

We were able to map in detail the characteristics, magnitude and speed of age-dependent maturation of BCR repertoires. Combining age-related variables using a PCA allowed clear separation of individuals younger than 10 years from older study participants, which was most pronounced in IgG repertoires. Our analysis now allows comparisons to be made in the BCR repertoires of healthy individuals to patients with altered immune states such as primary or secondary immunodeficiency $(4)$ or infectious disease $(59,60)$. By elucidating patterns that are associated with cumulative antigen exposure and an evolving immune system, this research offers important insight into adaptive immune system responses in humans. The mechanisms behind the development of clinically relevant autoimmunity is still poorly understood and the findings in this study show a substantial intrinsic capacity to produce self-reactive B cells, which may be essential to achieve the diversity needed for the defense against commensal pathogens in early life.

In summary, by studying the maturation of the healthy BCR repertoire with age, we found characteristics indicative of a maturing B-cell system consisting of alterations in immunoglobulin gene usage, increased levels of SHM associated with strong positive selection, and canonical class usage that differed considerably from germline structures. Repertoires from older individuals more frequently contained antibody using more downstream constant region genes that are involved in the immune response to polysaccharide antigens. With accumulating mutations, germline-encoded self-reactive antibody were seen less with advancing age indicating a possible beneficial role of self-reactive B-cells in the developing immune system. This study provides a reference data set of isotype subclass-specific BCR repertoires and stresses the importance of using well-selected, ageappropriate controls in future studies. 
bioRxiv preprint doi: https://doi.org/10.1101/609651; this version posted December 20, 2019. The copyright holder for this preprint (which was not certified by peer review) is the author/funder, who has granted bioRxiv a license to display the preprint in perpetuity. It is made available under aCC-BY-NC-ND 4.0 International license.

\section{References}

1. Reich, N. C. 2008. Janeway's Immunobiology . Seventh Edition. By Kenneth Murphy, Paul Travers, and, Mark Walport; contributions by, Michael Ehrenstein, Claudia Mauri, Allan Mowat, and, Andrey Shaw. Garland Science. New York: Taylor \&amp, 7th ed. (K. Murphy, P. Travers, and M. Walport, eds). Garland Science, New York and London.

2. Rawlings, D. J., G. Metzler, M. Wray-Dutra, and S. W. Jackson. 2017. Altered B cell signalling in autoimmunity. Nat. Rev. Immunol. 17: 421-436.

3. Hoffman, W., F. G. Lakkis, and G. Chalasani. 2016. B Cells, Antibodies, and More. Clin. J. Am. Soc. Nephrol. 11: 137-54.

4. Ghraichy, M., J. D. Galson, D. F. Kelly, and J. Trück. 2018. B-cell receptor repertoire sequencing in patients with primary immunodeficiency: a review. Immunology 153: 145-160.

5. Bashford-Rogers, R. J. M., K. G. C. Smith, and D. C. Thomas. 2018. Antibody repertoire analysis in polygenic autoimmune diseases. Immunology 155: 3-17.

6. Jiang, N., J. He, J. A. Weinstein, L. Penland, S. Sasaki, X. S. He, C. L. Dekker, N. Y. Zheng, M. Huang, M. Sullivan, P. C. Wilson, H. B. Greenberg, M. M. Davis, D. S. Fisher, and S. R. Quake. 2013. Lineage structure of the human antibody repertoire in response to influenza vaccination. Sci. Transl. Med. 5: 171ra19.

7. Galson, J. D., J. Trück, E. A. Clutterbuck, A. Fowler, V. Cerundolo, A. J. Pollard, G. Lunter, and D. F. Kelly. 2016. B-cell repertoire dynamics after sequential hepatitis $B$ vaccination and evidence for cross-reactive B-cell activation. Genome Med. 8: 68.

8. Galson, J. D., J. Trück, A. Fowler, M. Münz, V. Cerundolo, A. J. Pollard, G. Lunter, and D. F. Kelly. 2015. In-depth assessment of within-individual and inter-individual variation in the B cell receptor repertoire. Front. Immunol. 6: 113.

9. Galson, J. D., E. A. Clutterbuck, J. Trück, M. N. Ramasamy, M. Münz, A. Fowler, V. Cerundolo, A. J. Pollard, G. Lunter, and D. F. Kelly. 2015. BCR repertoire sequencing: Different patterns of B-cell activation after two Meningococcal vaccines. Immunol. Cell Biol. 93: 885-895.

10. Kovaltsuk, A., J. Leem, S. Kelm, J. Snowden, C. M. Deane, and K. Krawczyk. 2018. Observed Antibody Space: A Resource for Data Mining Next-Generation Sequencing of Antibody Repertoires. J. Immunol. 201: 2502-2509.

11. IJspeert, H., P. A. van Schouwenburg, D. van Zessen, I. Pico-Knijnenburg, G. J. Driessen, A. P. Stubbs, and M. van der Burg. 2016. Evaluation of the antigen-experienced B-cell receptor repertoire in healthy children and adults. Front. Immunol. 7: 410.

12. Comans-Bitter, W. M., R. De Groot, R. Van den Beemd, H. J. Neijens, W. C. J. Hop, K. Groeneveld, H. Hooijkaas, and J. J. M. Van Dongen. 1997. Immunophenotyping of blood lymphocytes in childhood: Reference values for lymphocyte subpopulations. J. Pediatr. 130: 388-393.

13. Vander Heiden, J. A., G. Yaari, M. Uduman, J. N. H. Stern, K. C. O'connor, D. A. Hafler, F. Vigneault, and S. H. Kleinstein. 2014. PRESTO: A toolkit for processing high-throughput sequencing raw reads of lymphocyte receptor repertoires. Bioinformatics 30: 1930-1932.

14. Gupta, N. T., J. A. Vander Heiden, M. Uduman, D. Gadala-Maria, G. Yaari, and S. H. Kleinstein. 2015. ChangeO: A toolkit for analyzing large-scale B cell immunoglobulin repertoire sequencing data. Bioinformatics 31: 33563358.

15. Ye, J., N. Ma, T. L. Madden, and J. M. Ostell. 2013. IgBLAST: an immunoglobulin variable domain sequence analysis tool. Nucleic Acids Res. 41: W34-W40.

16. Lunter, G., and M. Goodson. 2011. Stampy: A statistical algorithm for sensitive and fast mapping of Illumina sequence reads. Genome Res. 21: 936-939.

17. Stern, J. N. H., G. Yaari, J. A. Vander Heiden, G. Church, W. F. Donahue, R. Q. Hintzen, A. J. Huttner, J. D. Laman, R. M. Nagra, A. Nylander, D. Pitt, S. Ramanan, B. A. Siddiqui, F. Vigneault, S. H. Kleinstein, D. A. Hafler, and K. C. O'Connor. 2014. B cells populating the multiple sclerosis brain mature in the draining cervical lymph nodes. Sci. Transl. Med. 6: 248ra107-248ra107.

18. Yaari, G., M. Uduman, and S. H. Kleinstein. 2012. Quantifying selection in high-throughput Immunoglobulin sequencing data sets. Nucleic Acids Res. 40: 1-10.

19. Kovaltsuk, A., M. I. J. Raybould, W. K. Wong, C. Marks, S. Kelm, J. Snowden, J. Trück, and C. M. Deane. 2019. Structural Diversity of B-Cell Receptor Repertoires along the B-cell Differentiation Axis in Humans and Mice. bioRxiv 762880 .

20. Lefranc, M. P., C. Pommié, M. Ruiz, V. Giudicelli, E. Foulquier, L. Truong, V. Thouvenin-Contet, and G. Lefranc. 2003. IMGT unique numbering for immunoglobulin and $T$ cell receptor variable domains and Ig superfamily $V$-like 
bioRxiv preprint doi: https://doi.org/10.1101/609651; this version posted December 20, 2019. The copyright holder for this preprint (which was not certified by peer review) is the author/funder, who has granted bioRxiv a license to display the preprint in perpetuity. It is made available under aCC-BY-NC-ND 4.0 International license.

domains. Dev. Comp. Immunol. 27: 55-77.

21. Dunbar, J., and C. M. Deane. 2015. ANARCI: Antigen receptor numbering and receptor classification. Bioinformatics 32: 298-300.

22. Kovaltsuk, A., K. Krawczyk, S. Kelm, J. Snowden, and C. M. Deane. 2018. Filtering Next-Generation Sequencing of the Ig Gene Repertoire Data Using Antibody Structural Information. J. Immunol. 201: 3694-3704.

23. Wong, W. K., G. Georges, F. Ros, S. Kelm, A. P. Lewis, B. Taddese, J. Leem, and C. M. Deane. 2019. SCALOP: Sequence-based antibody canonical loop structure annotation. Bioinformatics 35: 1774-1776.

24. Choi, Y., and C. M. Deane. 2010. FREAD revisited: Accurate loop structure prediction using a database search algorithm. Proteins Struct. Funct. Bioinforma. 78: 1431-1440.

25. Berman, H., K. Henrick, H. Nakamura, and J. L. Markley. 2007. The worldwide Protein Data Bank (wwPDB): Ensuring a single, uniform archive of PDB data. Nucleic Acids Res. 35.

26. R Core Team. 2019. R: A language and environment for statistical computing. .

27. Wickham, H. 2016. ggplot2: Elegant Graphics for Data Analysis,. Springer-Verlag New York.

28. Kassambara, A. 2019. ggpubr: "ggplot2" Based Publication Ready Plots. R Packag. version 0.1.8. .

29. Gu, Z., R. Eils, and M. Schlesner. 2016. Complex heatmaps reveal patterns and correlations in multidimensional genomic data. Bioinformatics 32: 2847-2849.

30. Kassambara, A., and F. Mundt. 2017. Package "factoextra" for R: Extract and Visualize the Results of Multivariate Data Analyses. R Packag. version .

31. Luo, S., J. A. Yu, and Y. S. Song. 2016. Estimating Copy Number and Allelic Variation at the Immunoglobulin Heavy Chain Locus Using Short Reads. PLoS Comput. Biol. 12: e1005117.

32. Rubelt, F., C. E. Busse, S. A. C. Bukhari, J. P. Bürckert, E. Mariotti-Ferrandiz, L. G. Cowell, C. T. Watson, N. Marthandan, W. J. Faison, U. Hershberg, U. Laserson, B. D. Corrie, M. M. Davis, B. Peters, M. P. Lefranc, J. K. Scott, F. Breden, E. T. Luning Prak, and S. H. Kleinstein. 2017. Adaptive Immune Receptor Repertoire Community recommendations for sharing immune-repertoire sequencing data. Nat. Immunol. 18: 1274-1278.

33. Glanville, J., T. C. Kuo, H.-C. von Budingen, L. Guey, J. Berka, P. D. Sundar, G. Huerta, G. R. Mehta, J. R. Oksenberg, S. L. Hauser, D. R. Cox, A. Rajpal, and J. Pons. 2011. Naive antibody gene-segment frequencies are heritable and unaltered by chronic lymphocyte ablation. Proc. Natl. Acad. Sci. 108: 20066-20071.

34. Briney, B., A. Inderbitzin, C. Joyce, and D. R. Burton. 2019. Commonality despite exceptional diversity in the baseline human antibody repertoire. Nature 566: 393-397.

35. Donisi, P. M., N. Di Lorenzo, M. Riccardi, A. Paparella, C. Sarpellon, S. Zupo, G. Bertoldero, C. Minotto, and V. Stracca-Pansa. 2006. Pattern and distribution of immunoglobulin VH gene usage in a cohort of B-CLL patients from a northeastern region of Italy. Diagnostic Mol. Pathol. 15: 206-215.

36. Widhopf, G. F., L. Z. Rassenti, T. L. Toy, J. G. Gribben, W. G. Wierda, and T. J. Kipps. 2004. Chronic lymphocytic leukemia B cells of more than $1 \%$ of patients express virtually identical immunoglobulins. Blood 104: 2499-2504.

37. North, B., A. Lehmann, and R. L. Dunbrack. 2011. A new clustering of antibody CDR loop conformations. J. Mol. Biol. 406: 228-256.

38. Chothia, C., and A. M. Lesk. 1987. Canonical structures for the hypervariable regions of immunoglobulins. J. Mol. Biol. 196: 901-917.

39. Tsioris, K., N. T. Gupta, A. O. Ogunniyi, R. M. Zimnisky, F. Qian, Y. Yao, X. Wang, J. N. H. Stern, R. Chari, A. W. Briggs, C. R. Clouser, F. Vigneault, G. M. Church, M. N. Garcia, K. O. Murray, R. R. Montgomery, S. H. Kleinstein, and J. C. Love. 2015. Neutralizing antibodies against West Nile virus identified directly from human B cells by singlecell analysis and next generation sequencing. Integr. Biol. 7: 1587-1597.

40. Wardemann, H., S. Yurasov, A. Schaefer, J. W. Young, E. Meffre, and M. C. Nussenzweig. 2003. Predominant autoantibody production by early human B cell precursors. Science (80-. ). 301: 1374-1377.

41. Larimore, K., M. W. McCormick, H. S. Robins, and P. D. Greenberg. 2012. Shaping of Human Germline IgH Repertoires Revealed by Deep Sequencing. J. Immunol. 189: 3221-3230.

42. Pugh-Bernard, A. E., G. J. Silverman, A. J. Cappione, M. E. Villano, D. H. Ryan, R. A. Insel, and I. Sanz. 2001. Regulation of inherently autoreactive VH4-34 B cells in the maintenance of human B cell tolerance. J. Clin. Invest. 108: 1061-1070.

43. Potter, K. N., P. Hobby, S. Klijn, F. K. Stevenson, and B. J. Sutton. 2002. Evidence for involvement of a hydrophobic patch in framework region 1 of human V4-34-encoded Igs in recognition of the red blood cell I antigen. 
bioRxiv preprint doi: https://doi.org/10.1101/609651; this version posted December 20, 2019. The copyright holder for this preprint (which was not certified by peer review) is the author/funder, who has granted bioRxiv a license to display the preprint in perpetuity. It is made available under aCC-BY-NC-ND 4.0 International license.

J. Immunol. 169: 3777-3782.

44. Reed, J. H., J. Jackson, D. Christ, and C. C. Goodnow. 2016. Clonal redemption of autoantibodies by somatic hypermutation away from self-reactivity during human immunization. J. Exp. Med. 213: 1255-1265.

45. Sabouri, Z., P. Schofield, K. Horikawa, E. Spierings, D. Kipling, K. L. Randall, D. Langley, B. Roome, R. Vazquez-Lombardi, R. Rouet, J. Hermes, T. D. Chan, R. Brink, D. K. Dunn-Walters, D. Christ, and C. C. Goodnow. 2014. Redemption of autoantibodies on anergic B cells by variable-region glycosylation and mutation away from selfreactivity. Proc. Natl. Acad. Sci. 111: E2567-E2575.

46. Tabibian-Keissar, H., L. Hazanov, G. Schiby, N. Rosenthal, A. Rakovsky, M. Michaeli, G. L. Shahaf, Y. Pickman, K. Rosenblatt, D. Melamed, D. Dunn-Walters, R. Mehr, and I. Barshack. 2016. Aging affects B-cell antigen receptor repertoire diversity in primary and secondary lymphoid tissues. Eur. J. Immunol. 46: 480-492.

47. Schatorjé, E. J. H., G. J. Driessen, R. W. N. M. van Hout, M. van der Burg, and E. de Vries. 2014. Levels of somatic hypermutations in B cell receptors increase during childhood. Clin. Exp. Immunol. 178: 394-398.

48. Siegrist, C. A., and R. Aspinall. 2009. B-cell responses to vaccination at the extremes of age. Nat. Rev. Immunol. 9: 185-194.

49. Fecteau, J. F., G. Cote, and S. Neron. 2006. A New Memory CD27-IgG+ B Cell Population in Peripheral Blood Expressing VH Genes with Low Frequency of Somatic Mutation. J. Immunol. 177: 3728-3736.

50. Nagumo, H., K. Agematsu, N. Kobayashi, K. Shinozaki, S. Hokibara, H. Nagase, M. Takamoto, K. Yasui, K. Sugane, and A. Komiyama. 2002. The different process of class switching and somatic hypermutation; a novel analysis by CD27-naive B cells. Blood 99: 567-575.

51. Kovaltsuk, A., K. Krawczyk, J. D. Galson, D. F. Kelly, C. M. Deane, and J. Trück. 2017. How B-cell receptor repertoire sequencing can be enriched with structural antibody data. Front. Immunol. 8: 1753.

52. Krawczyk, K., S. Kelm, A. Kovaltsuk, J. D. Galson, D. Kelly, J. Trück, C. Regep, J. Leem, W. K. Wong, J. Nowak, J. Snowden, M. Wright, L. Starkie, A. Scott-Tucker, J. Shi, and C. M. Deane. 2018. Structurally mapping antibody repertoires. Front. Immunol. 9.

53. Blanco, E., M. Pérez-Andrés, S. Arriba-Méndez, T. Contreras-Sanfeliciano, I. Criado, O. Pelak, A. SerraCaetano, A. Romero, N. Puig, A. Remesal, J. Torres Canizales, E. López-Granados, T. Kalina, A. E. Sousa, M. van Zelm, M. van der Burg, J. J. M. van Dongen, and A. Orfao. 2018. Age-associated distribution of normal B-cell and plasma cell subsets in peripheral blood. J. Allergy Clin. Immunol. 141: 2208-2219.e16.

54. Vidarsson, G., G. Dekkers, and T. Rispens. 2014. IgG subclasses and allotypes: From structure to effector functions. Front. Immunol. 5: 520.

55. Woof, J. M., and M. A. Kerr. 2004. IgA function - Variations on a theme. Immunology 113: 175-177.

56. Turner, P., C. Turner, N. Green, L. Ashton, E. Lwe, A. Jankhot, N. P. Day, N. J. White, F. Nosten, and D. Goldblatt. 2013. Serum antibody responses to pneumococcal colonization in the first 2 years of life: Results from an SE Asian longitudinal cohort study. Clin. Microbiol. Infect. 19: 1-8.

57. Xiong, H., J. Dolpady, M. Wabl, M. A. Curotto de Lafaille, and J. J. Lafaille. 2012. Sequential class switching is required for the generation of high affinity IgE antibodies. J. Exp. Med. 209: 353-364.

58. Schickel, J.-N., S. Glauzy, Y.-S. Ng, N. Chamberlain, C. Massad, I. Isnardi, N. Katz, G. Uzel, S. M. Holland, C. Picard, A. Puel, J.-L. Casanova, and E. Meffre. 2017. Self-reactive VH4-34-expressing IgG B cells recognize commensal bacteria. J. Exp. Med. 214: 1991-2003.

59. Hou, D., C. Chen, E. J. Seely, S. Chen, and Y. Song. 2016. High-throughput sequencing-based immune repertoire study during infectious disease. Front. Immunol. 7: 336.

60. Burkholder, W. F., E. W. Newell, M. Poidinger, S. Chen, and K. Fink. 2017. Deep Sequencing in Infectious Diseases: Immune and Pathogen Repertoires for the Improvement of Patient Outcomes. Front. Immunol. 8: 593. 


\section{Supplementary information}

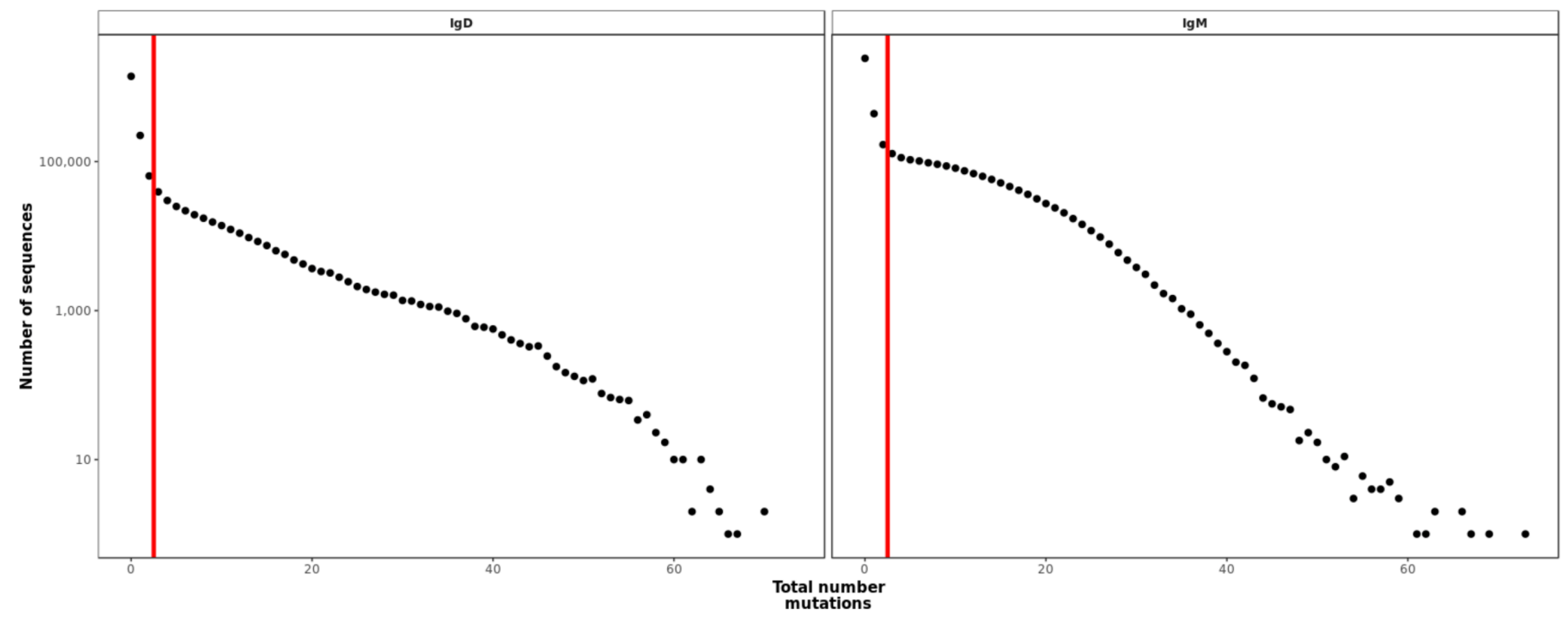

Supplementary figure 1 Distribution of somatic hypermutation in all IgD and IgM transcripts. The vertical line indicates the threshold chosen (mutation $\mathrm{n}$ between 2 and 3) to separate naïve and memory repertoires for $\operatorname{lgM}$ and $\lg D$ sequences.
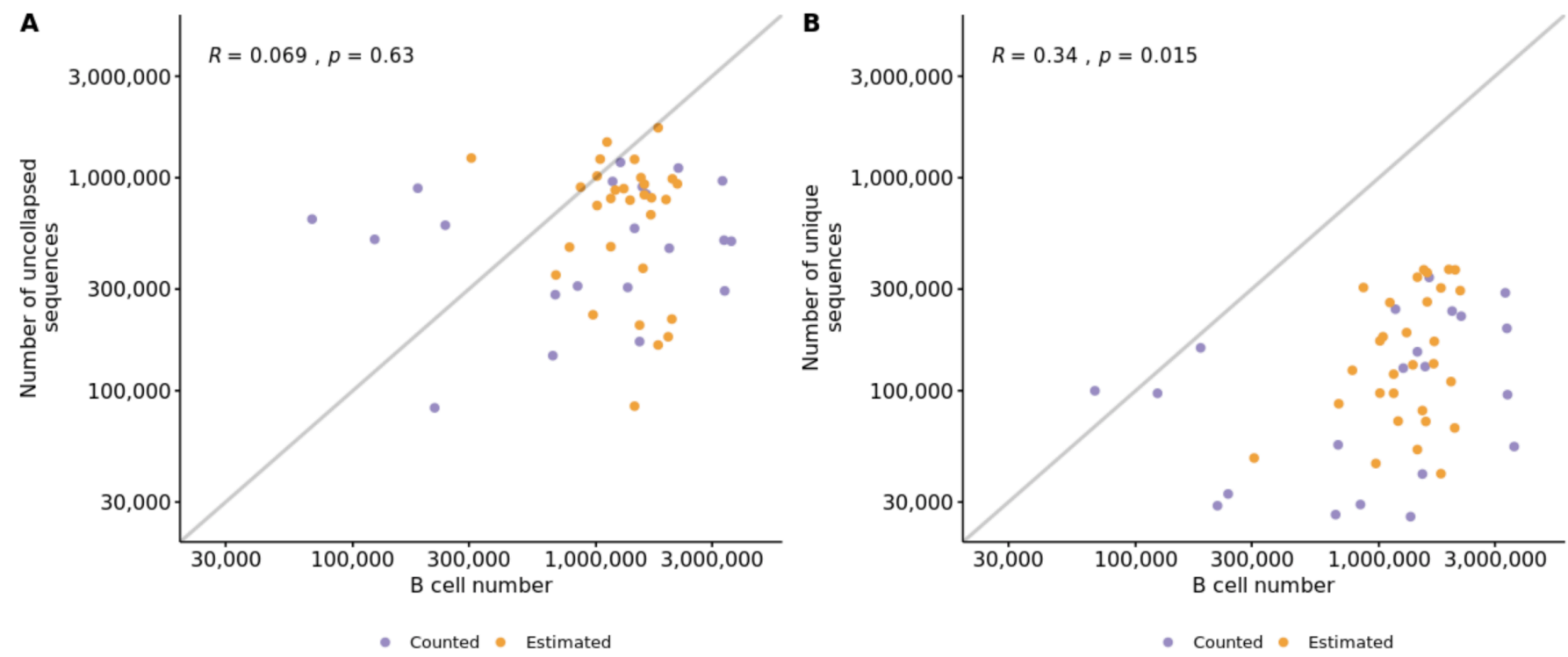

Supplementary figure 2: Correlation between cell number in a sample, and the number of sequences for that sample $A$ before and $B$ after collapsing (Pearson correlation coefficient). The B-cell number was either based on actual counts or estimated using PBMC counts and the median percentage of age-dependent reference values. 
bioRxiv preprint doi: https://doi.org/10.1101/609651; this version posted December $20,2019$. The copyright holder for this preprint (which was not certified by peer review) is the author/funder, who has granted bioRxiv a license to display the preprint in perpetuity. It is made available under aCC-BY-NC-ND 4.0 International license.

A

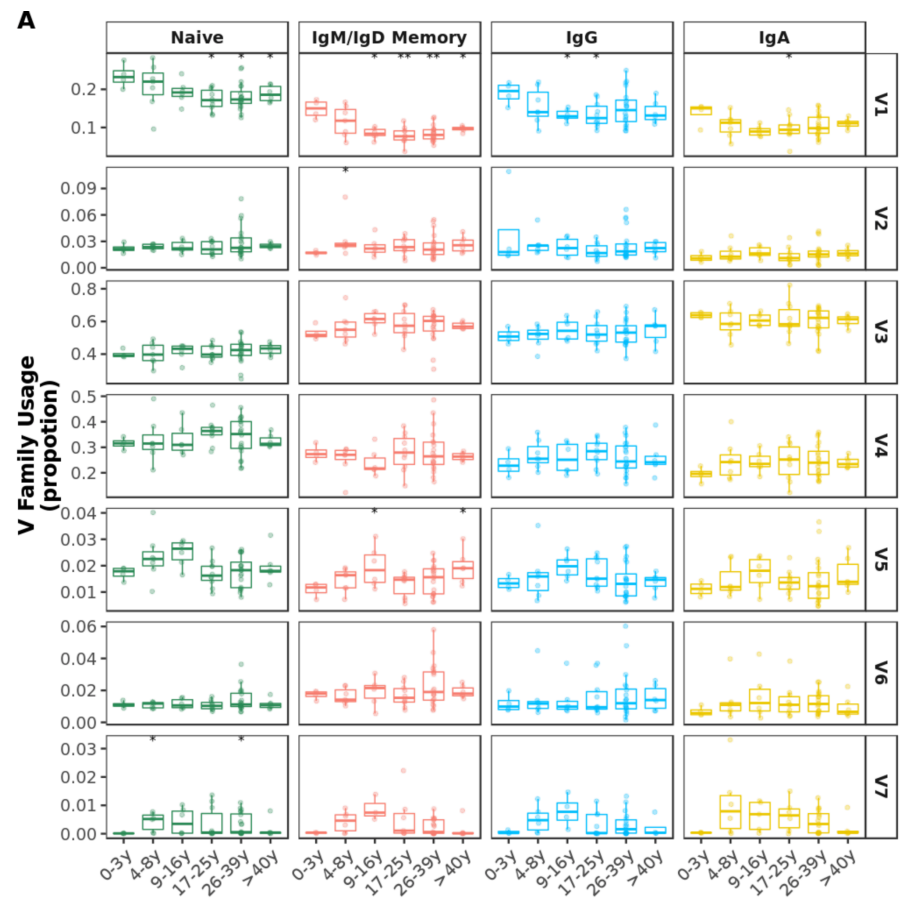

B

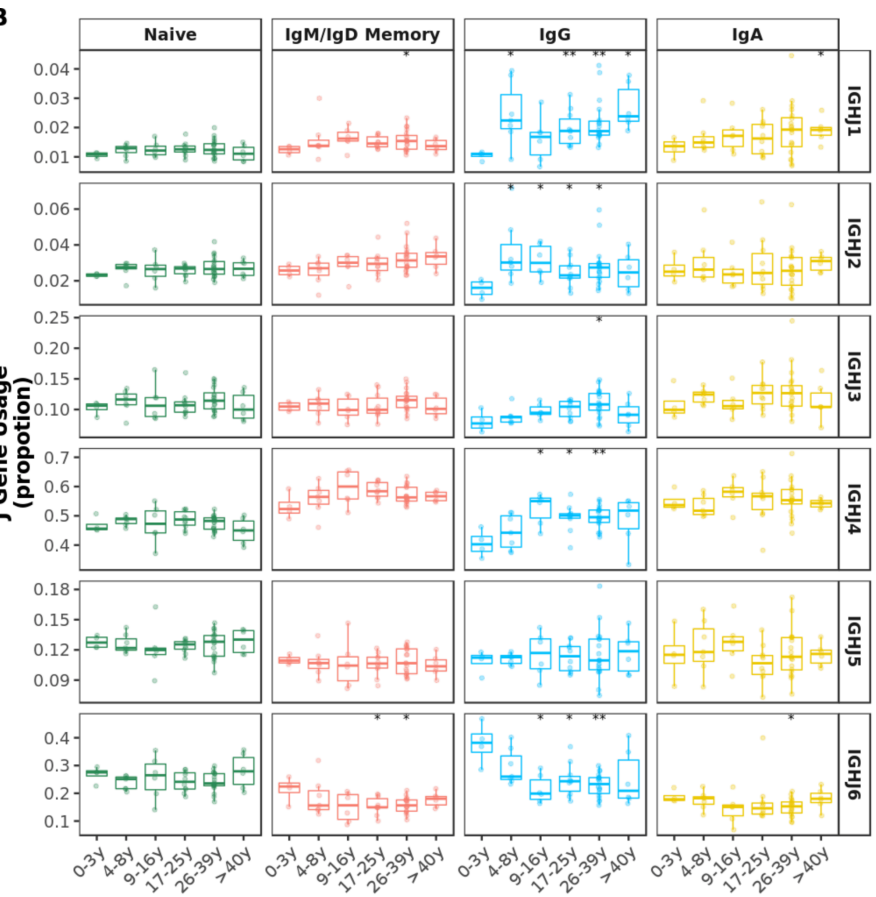

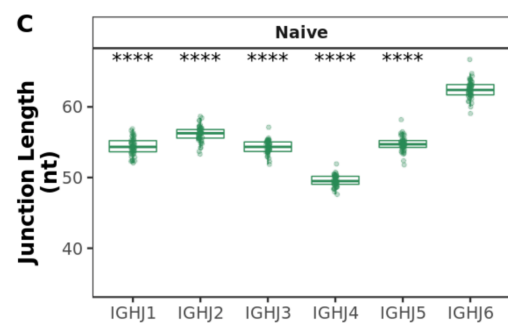
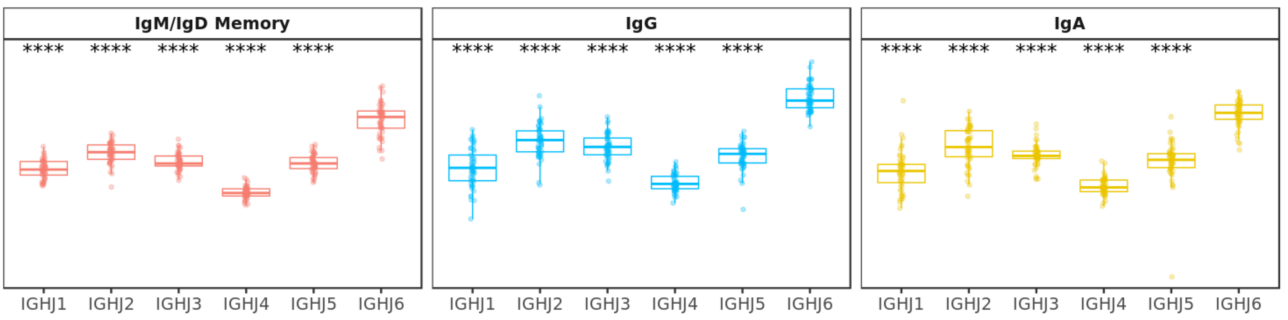

Supplementary figure $3 A \vee$ family and $B \mathrm{~J}$ gene usage by age band. Comparison of each age group to the $0-3 y$ group was performed using the Wilcoxon test. C IGHJ6 transcripts show significantly longer junctions. Comparison of each gene to IGHJ6 was performed using the Wilcoxon test. ${ }^{*} p<0.05,{ }^{* *} p<0.01,{ }^{* * *} p<0.001,{ }^{* * * *} p<0.0001$
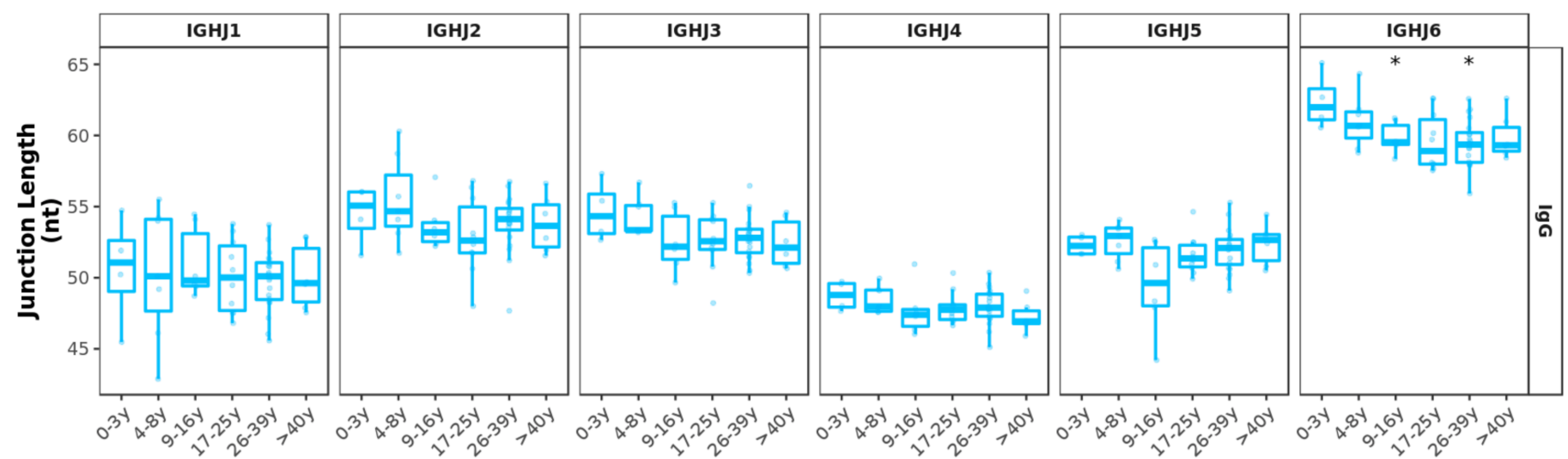

Supplementary Figure 4: Junction length decrease in IgG transcripts is still apparent within $\mathrm{J}$ gene and is only significant in transcripts with IGHJ6. Comparison of each age group to the $0-3 y$ group was performed using the Wilcoxon test. ${ }^{*} p<0.05$ 
bioRxiv preprint doi: https://doi.org/10.1101/609651; this version posted December 20, 2019. The copyright holder for this preprint (which was not certified by peer review) is the author/funder, who has granted bioRxiv a license to display the preprint in perpetuity. It is made available under aCC-BY-NC-ND 4.0 International license.

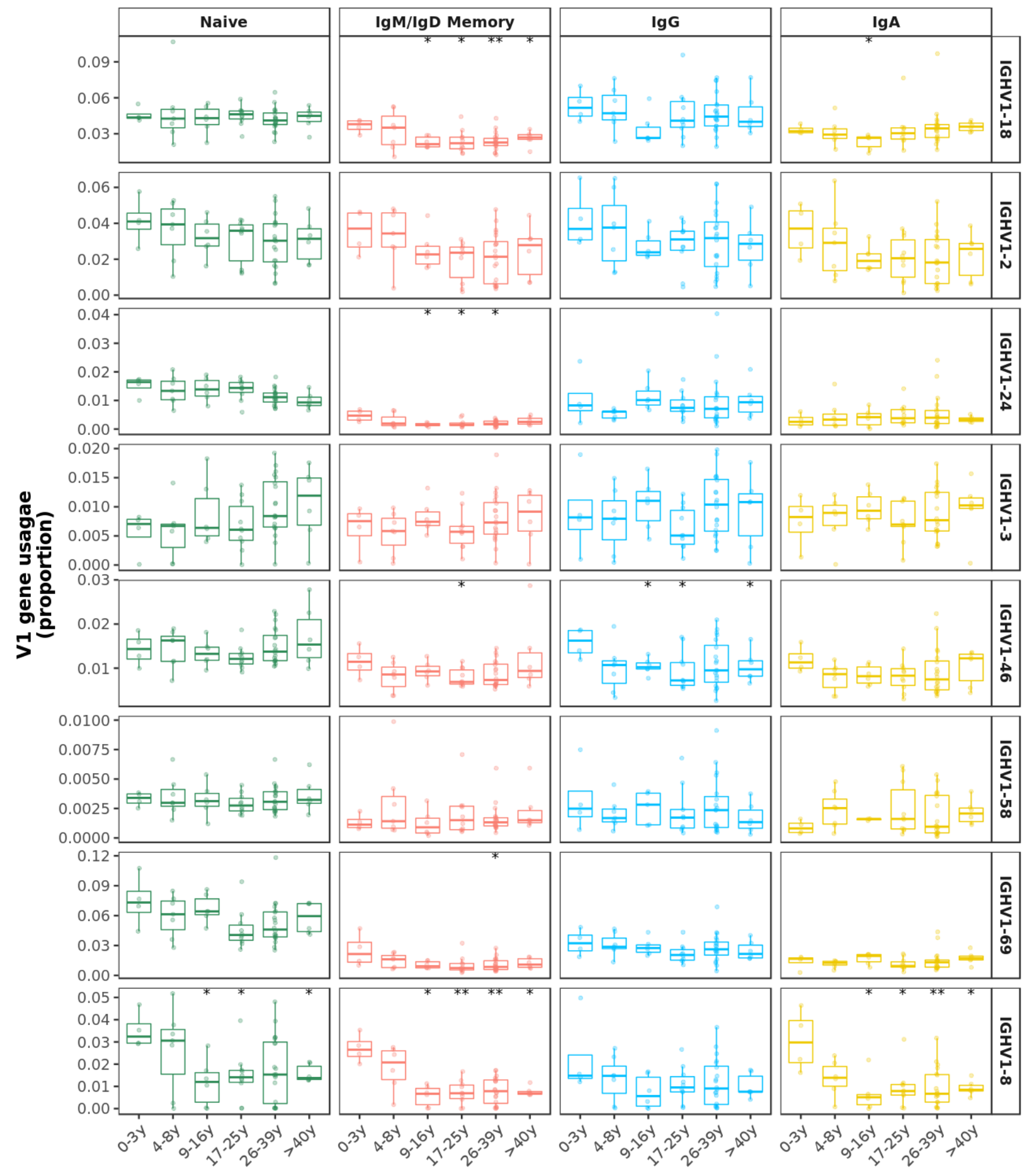

Supplementary figure 5 Proportion of the top 8 V1 family genes by age band. The decrease seen in V1 family usage is a result of a decrease in multiple individual genes. Comparison of each age group to the 0-3y group was performed using the Wilcoxon test. ${ }^{*} p<0.05,{ }^{* *} p<0.01$ 
bioRxiv preprint doi: https://doi org/101101/609651; this version posted December 20,2019 . The copyright holder for this preprint (which was not certified by peer review) is the author/funder, who has granted bioRxiv a license to display the preprint in perpetuity. It is made available under aCC-BY-NC-ND 4.0 International license.

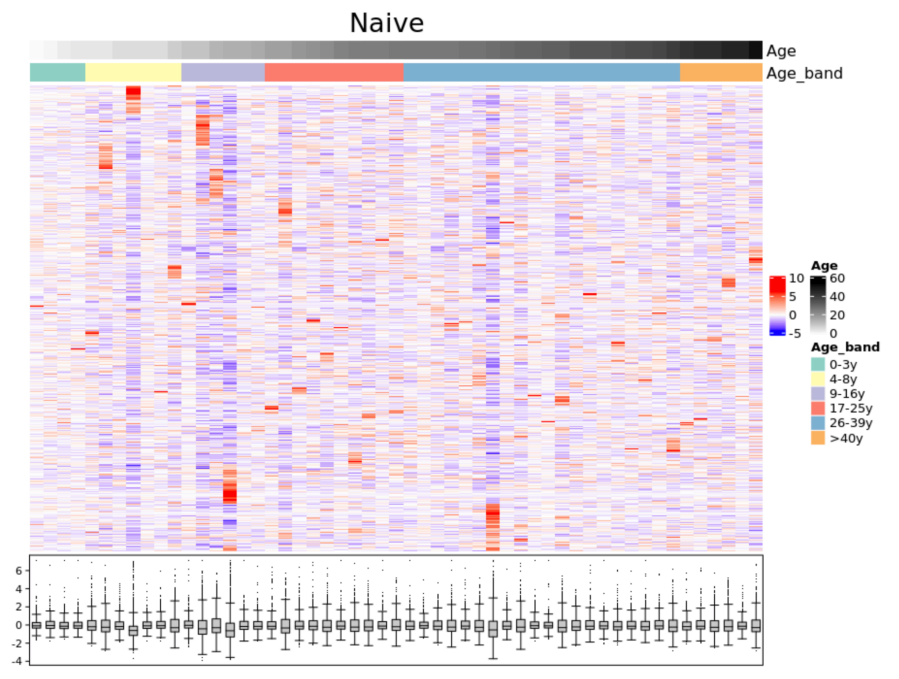

$\lg G$

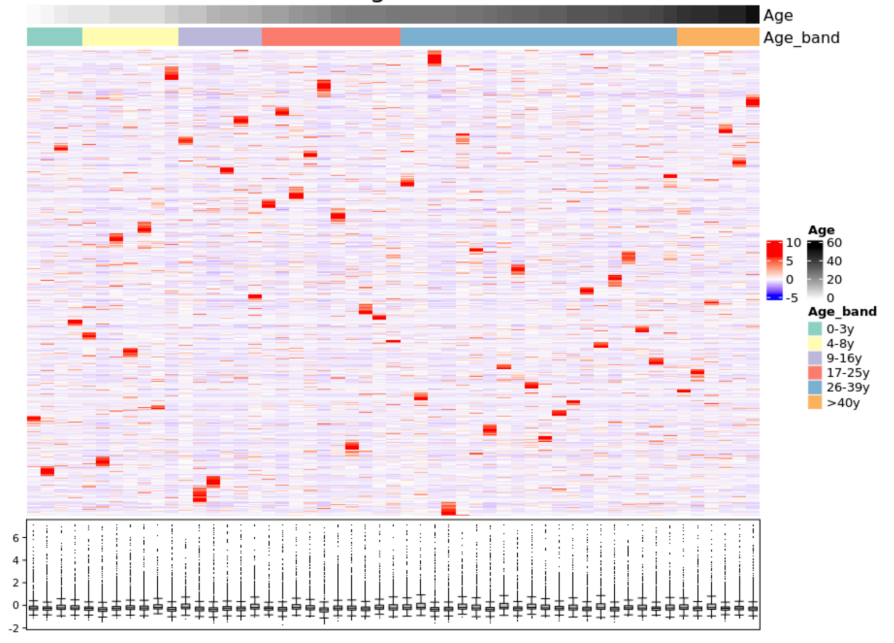

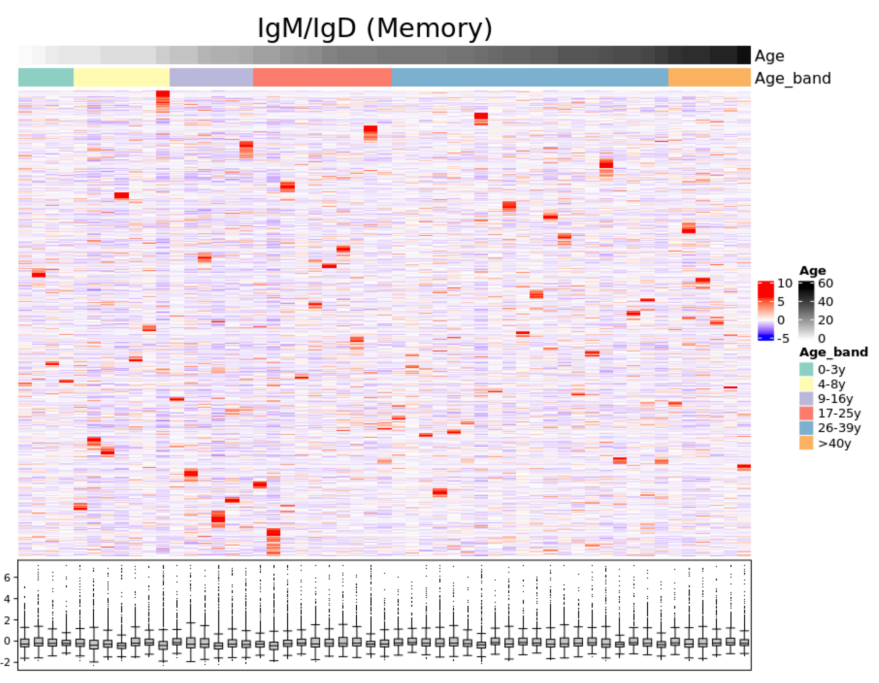

$\lg A$

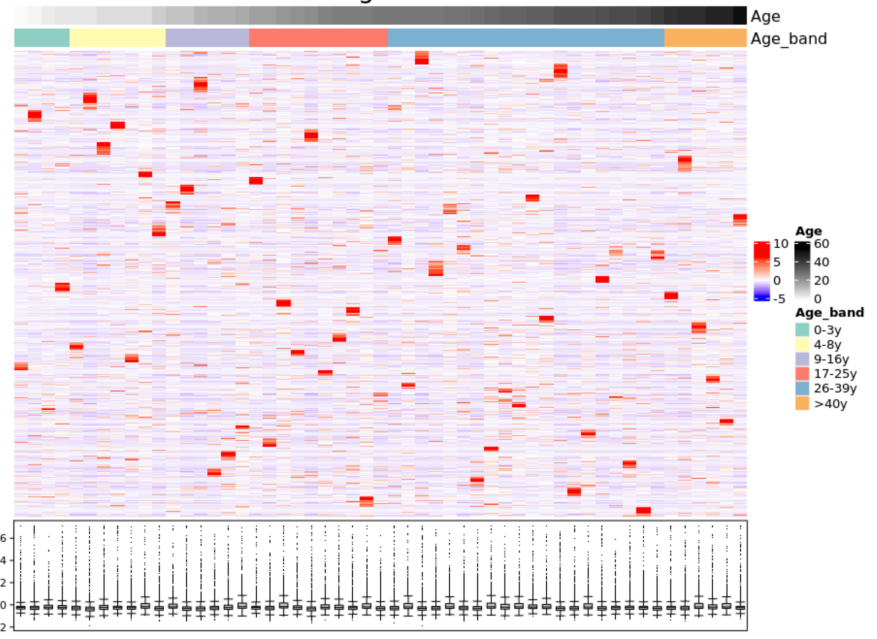

Supplementary Figure 6 The structural composition of the naïve, IgM/lgD memory and class-switched IgG and IgA repertoires. Heatmaps are normalized by row which represents usage of one PDB cluster. Distributions of the normalized PDB cluster usage by individual is shown as a boxplot. Samples (columns) are ordered by age and PDB clusters (rows) are hierarchically clustered. 
bioRxiv preprint doi: https://doi.org/10.1101/609651; this version posted December 20, 2019. The copyright holder for this preprint (which was not certified by peer review) is the author/funder, who has granted bioRxiv a license to display the preprint in perpetuity. It is made available under aCC-BY-NC-ND 4.0 International license.
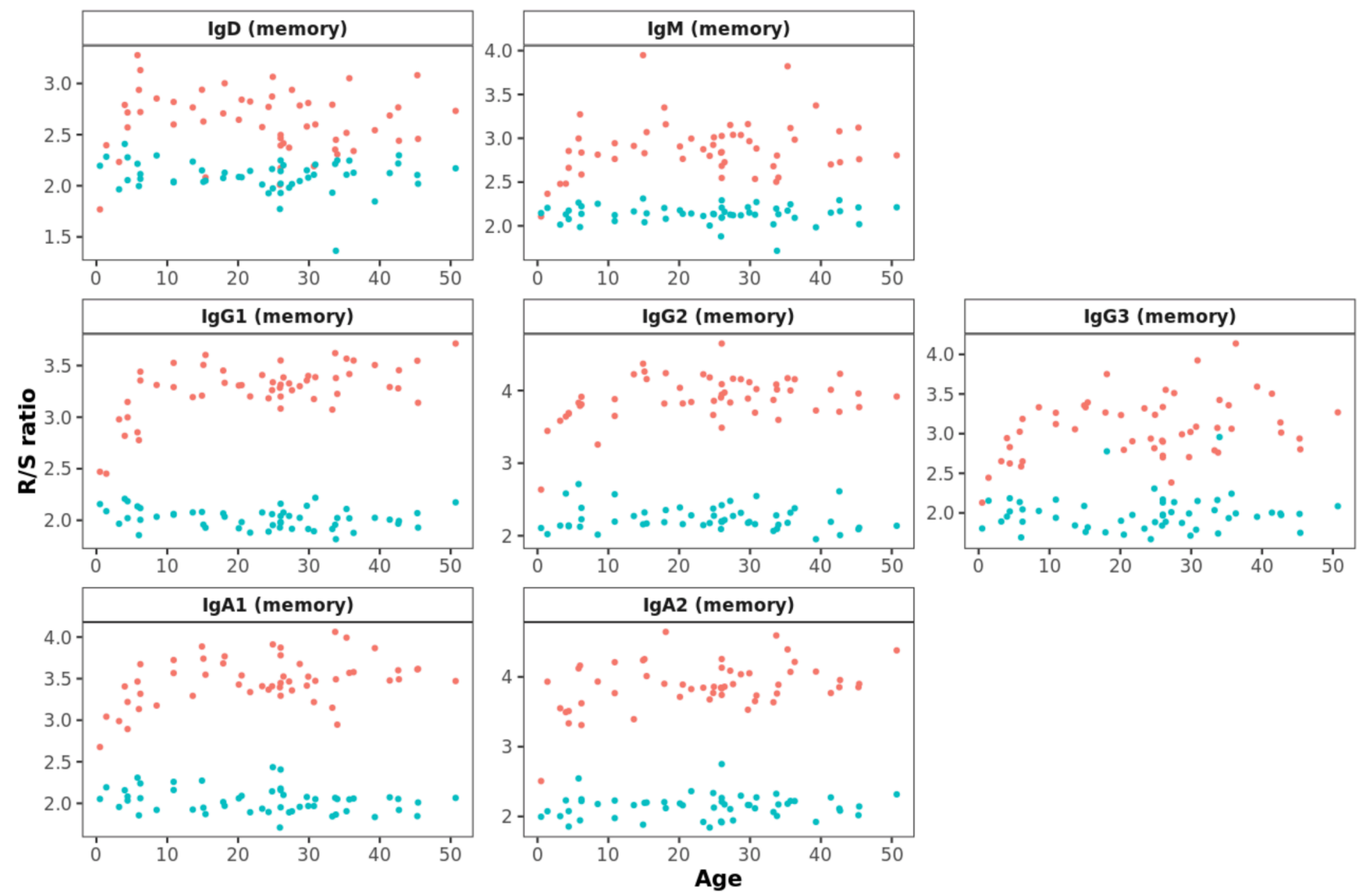

R/S ratio in
CDRs
FWRs

Supplementary figure $7 \mathrm{R} / \mathrm{S}$ ratio in FWRs does not correlate with age and is lower compared with CDRs.
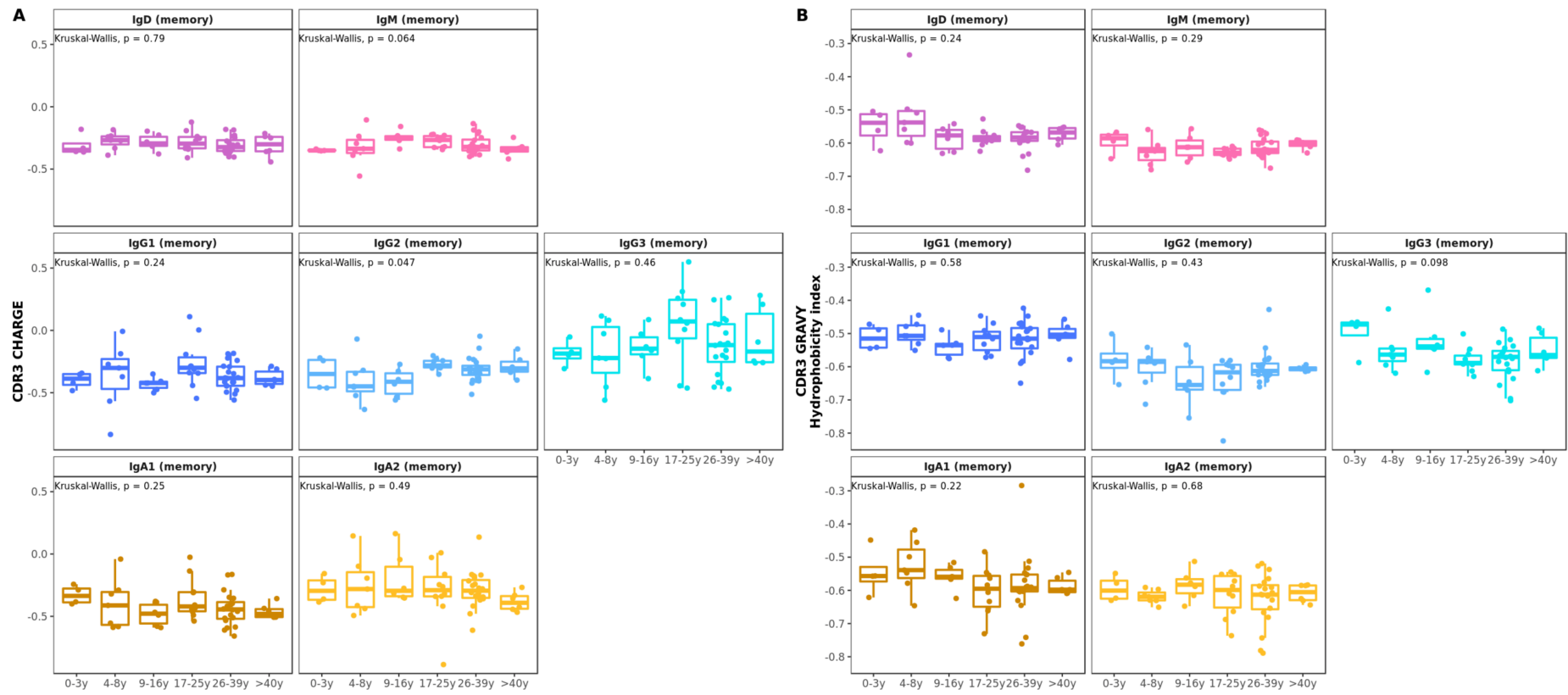

Supplementary figure $8 A$ CDR3 charge and $B$ CDR3 hydrophobicity index do not correlate with age in healthy controls. 


\section{Supplementary table 1}

\begin{tabular}{|c|c|c|c|c|c|c|c|c|c|c|c|c|c|c|c|c|c|c|c|c|}
\hline Participant & Sex & $\operatorname{Age}(y)$ & $\begin{array}{c}\text { Cell } \\
\text { type }\end{array}$ & $\begin{array}{l}\text { PBMC } \\
\text { number }\end{array}$ & $\begin{array}{l}\text { B cell } \\
\text { number }\end{array}$ & $\begin{array}{l}\text { B cells estimated } \\
\text { (E) or counted (C) }\end{array}$ & RT PCR & $\begin{array}{l}\text { Raw } \\
\text { Sequences }\end{array}$ & $\begin{array}{l}\text { Unique Productive } \\
\text { Sequences }\end{array}$ & $\begin{array}{l}\text { IgD } \\
\text { (naive) }\end{array}$ & $\begin{array}{l}\lg M \\
\text { (naive) }\end{array}$ & $\begin{array}{l}\text { IgD } \\
\text { (memory) }\end{array}$ & $\begin{array}{l}\operatorname{lgM} \\
\text { (memory) }\end{array}$ & $\begin{array}{l}\operatorname{lgG} 1 \\
\text { (memory) }\end{array}$ & $\begin{array}{l}\operatorname{lgG} 2 \\
\text { (memory) }\end{array}$ & $\begin{array}{l}\operatorname{lgG} 3 \\
\text { (memory) }\end{array}$ & $\begin{array}{l}\text { IgG4 } \\
\text { (Memory) }\end{array}$ & $\begin{array}{l}\text { IgA1 } \\
\text { (Memory) }\end{array}$ & $\begin{array}{l}\text { IgA2 } \\
\text { (memory) }\end{array}$ & $\begin{array}{l}\operatorname{lgE} \\
\text { (memory) }\end{array}$ \\
\hline $\mathrm{HC}_{-} 1$ & $F$ & 0.5 & PBMCs & 14400000 & 3024000 & $\mathrm{E}$ & AEG,MD & 1904663 & 285839 & 72572 & 159399 & 2240 & 7963 & 21480 & 4276 & 4875 & $\frac{1078}{38}$ & 9509 & 3429 & \\
\hline $\mathrm{HC}_{-} 2$ & $\mathrm{~F}$ & 1.4 & PBMCs & 6900000 & 1932000 & E & AEG,MD & 2326250 & 239052 & 62659 & 132670 & 5230 & 11630 & 16237 & 1263 & 3647 & 18 & 4585 & 1111 & 2 \\
\hline $\mathrm{HC}_{-}{ }_{3}$ & M & 3.2 & PBMCs & 9900000 & 2376000 & $\mathrm{E}$ & $A E G, M D$ & 1622639 & 221134 & 52374 & 115799 & 3386 & 18607 & 11164 & 4741 & 1819 & 54 & 9894 & 3246 & 50 \\
\hline HC_4 & $\mathrm{F}$ & 3.9 & PBMCs & 9450000 & 2268000 & $\mathrm{E}$ & AEG,MD & 1571312 & 337616 & 55542 & 156394 & 14433 & 35134 & 35350 & 6421 & 7459 & 46 & 22599 & 4230 & 8 \\
\hline HC_5 & $\mathrm{F}$ & 4.4 & PBMCs & 4200000 & 1008000 & $\mathrm{E}$ & AEG,MD & 1975420 & 93299 & 20948 & 44505 & 2070 & 10982 & 5957 & 3788 & 1587 & 42 & 2099 & 1280 & 41 \\
\hline HC_6 & M & 4.4 & PBMCs & 1140000 & 273600 & $\mathrm{E}$ & AEG,MD & 1216544 & 28674 & 13955 & 9161 & 1689 & 1786 & 872 & 341 & 122 & 4 & 599 & 141 & 4 \\
\hline $\mathrm{HC}_{-}{ }^{7}$ & $\mathrm{~F}$ & 5.8 & PBMCs & 11100000 & 1998000 & $\mathrm{E}$ & AEG,MD & 1973589 & 128326 & 35276 & 44614 & 10339 & 9463 & 13050 & 5047 & 1526 & 53 & 7791 & 1164 & 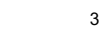 \\
\hline HC_8 & M & 6.0 & PBMCs & 12600000 & 2268000 & $\mathrm{E}$ & AEG,MD & 1818496 & 124567 & 7399 & 32174 & 1387 & 22205 & 37668 & 5395 & 5989 & 34 & 10097 & 2147 & 72 \\
\hline HC_9 & M & 6.2 & PBMCs & 6150000 & 1107000 & $\mathrm{E}$ & AEG,MD & 2474481 & 255693 & 84048 & 129241 & 4096 & 12182 & 5861 & 4610 & 1268 & 46 & 9844 & 4117 & 380 \\
\hline HC_10 & $\mathrm{F}$ & 6.2 & PBMCs & 10800000 & 1944000 & $\mathrm{E}$ & AEG,MD & 1337214 & 368861 & 29803 & 112882 & 7228 & 54220 & 42616 & 28527 & 7659 & 534 & 59361 & 25936 & 95 \\
\hline HC_11 & M & 8.5 & PBMCs & 10800000 & 1944000 & $\mathrm{E}$ & AEG,MD & 880759 & 40494 & 18417 & 10920 & 1431 & 3099 & 2283 & 841 & 725 & 19 & 2126 & 633 & 0 \\
\hline HC_12 & $\mathrm{F}$ & 10.9 & PBMCs & 12900000 & 2064000 & $\mathrm{E}$ & $\mathrm{AEG}, \mathrm{MD}$ & 1802230 & 366617 & 65222 & 148236 & 11720 & 72104 & 20972 & 10050 & 9851 & 427 & 19081 & 8746 & 208 \\
\hline HC_13 & $\mathrm{F}$ & 10.9 & PBMCs & 7920000 & 1267200 & $E$ & AEG,MD & 1168944 & 25242 & 6459 & 7505 & 1519 & 5248 & 1829 & 977 & 261 & 25 & 1057 & 275 & 87 \\
\hline HC_14 & $\mathrm{F}$ & 13.6 & PBMCs & 4740000 & 758400 & $\mathrm{E}$ & $\mathrm{AEG}, \mathrm{MD}$ & 872906 & 26006 & 8819 & 8659 & 2185 & 4714 & 278 & 644 & 70 & 5 & 450 & 173 & 9 \\
\hline HC_15 & $\mathrm{F}$ & 14.9 & PBMCs & 1920000 & 307200 & $E$ & AEG,MD & 2717449 & 44254 & 1632 & 3581 & 1259 & 17735 & 5991 & 3376 & 1053 & 238 & 5918 & 3464 & 7 \\
\hline HC_16 & M & 15.1 & PBMCs & 14700000 & 2352000 & $\mathrm{E}$ & AEG,MD & 659493 & 95429 & 40827 & 36587 & 2228 & 6421 & 1635 & 2474 & 384 & 67 & 3639 & 1056 & 111 \\
\hline HC_17 & $\mathrm{F}$ & 15.4 & PBMCs & NA & NA & NA & $\mathrm{AEG}, \mathrm{MD}$ & 995764 & 289287 & 41886 & 118609 & 4719 & 24748 & 37623 & 27409 & 6542 & 1142 & 24002 & 2592 & 15 \\
\hline HC_18 & $\mathrm{F}$ & 17.9 & PBMCs & 7200000 & 864000 & E & $\mathrm{AEG}, \mathrm{MD}$ & 1682823 & 302272 & 26679 & 68526 & 4680 & 55458 & 37658 & 10783 & 12027 & 1252 & 77485 & 7704 & 20 \\
\hline HC_19 & M & 18.1 & PBMCs & 8400000 & 1008000 & $\mathrm{E}$ & $\mathrm{AEG}, \mathrm{MD}$ & 1011146 & 28798 & 12418 & 7307 & 1269 & 2209 & 1350 & 870 & 158 & 151 & 2248 & 818 & 0 \\
\hline HC_2O & M & 20.1 & PBMCs & 13200000 & 1584000 & $\mathrm{E}$ & AEG,MD & 1433354 & 356105 & 42060 & 104452 & 5655 & 64801 & 39036 & 22756 & 4546 & 67 & 61075 & 11647 & 10 \\
\hline HC_21 & M & 20.5 & PBMCs & 9600000 & 1152000 & $\mathrm{E}$ & AEG,MD & 945221 & 96859 & 25143 & 28963 & 6092 & 21561 & 5861 & 3223 & 381 & 684 & 3195 & 1695 & 61 \\
\hline HC_22 & M & 21.7 & PBMCs & 15000000 & 1800000 & $E$ & $\mathrm{AEG}, \mathrm{MD}$ & 1140675 & 40591 & 21975 & 8263 & 4543 & 4454 & 294 & 178 & 244 & 1 & 477 & 160 & 2 \\
\hline HC_23 & $\mathrm{F}$ & 23.4 & PBMCs & 9000000 & 1080000 & $\mathrm{E}$ & AEG,MD & 1423314 & 151168 & 68644 & 25308 & 10563 & 9876 & 7757 & 11844 & 1094 & 88 & 12146 & 3815 & 33 \\
\hline HC_24 & $\mathrm{F}$ & 24.3 & CD19+ & & 3600000 & c & $\mathrm{AEG}, \mathrm{MD}$ & 1650432 & 53250 & 2584 & 27411 & 648 & 13631 & 2320 & 2099 & 628 & 26 & 2098 & 1803 & 2 \\
\hline HC_25 & $\mathrm{F}$ & 24.8 & PBMCs & 17100000 & 2052000 & $\mathrm{E}$ & $\mathrm{AEG}, \mathrm{MD}$ & 764310 & 66786 & 12784 & 24047 & 3933 & 17222 & 2397 & 1562 & 308 & 0 & 3145 & 1386 & 2 \\
\hline HC_26 & $\mathrm{F}$ & 24.9 & PBMCs & 18000000 & 2160000 & $\mathrm{E}$ & AEG,MD & 1683395 & 288827 & 35736 & 91187 & 6432 & 63062 & 18078 & 28519 & 2636 & 2025 & 26499 & 14562 & 91 \\
\hline HC_27 & M & 25.9 & PBMCs & 12000000 & 1440000 & $\mathrm{E}$ & Mix I & 593323 & 52933 & 7679 & 27223 & 1394 & 10655 & 2280 & 2011 & 432 & 17 & 509 & 728 & 5 \\
\hline HC_28 & $\mathrm{F}$ & 26.0 & PBMCs & 14000000 & 1680000 & $\mathrm{E}$ & Mix I & 1146458 & 133861 & 20396 & 54984 & 3362 & 27783 & 10845 & 10135 & 1339 & 123 & 2477 & 2399 & 18 \\
\hline HC_29 & $\mathrm{F}$ & 26.0 & CD19+ & & 2000000 & c & AEG,MD & 1710083 & 235120 & 30835 & 145027 & 3509 & 38873 & 5427 & 3685 & 1335 & 17 & 4627 & 1783 & 2 \\
\hline $\mathrm{HC}_{-} 30$ & $\mathrm{~F}$ & 26.0 & PBMCs & 3300000 & 185000 & c & $\mathrm{AEG}, \mathrm{MD}$ & 2347978 & 158947 & 49263 & 63128 & 7051 & 20867 & 6055 & 4737 & 1279 & 99 & 5434 & 1033 & 1 \\
\hline HC_31 & $\mathrm{F}$ & 26.0 & PBMCs & 1725000 & 68000 & c & AEG,MD & 1524836 & 99870 & 25370 & 29303 & 6741 & 23073 & 4476 & 3962 & 708 & 102 & 4847 & 1288 & 0 \\
\hline HC_32 & $\mathrm{F}$ & 26.4 & PBMCs & 14100000 & 1692000 & $\mathrm{E}$ & AEG,MD & 1581380 & 168295 & 56857 & 51011 & 4527 & 10671 & 12723 & 6925 & 6070 & 230 & 13898 & 5288 & 95 \\
\hline HC_33 & $\mathrm{F}$ & 27.2 & PBMCs & 13000000 & 1560000 & $E$ & Mix I & 1217105 & 71742 & 8699 & 28815 & 1976 & 22157 & 4257 & 2197 & 1173 & 36 & 1479 & 953 & 0 \\
\hline $\mathrm{HC}_{-} 34$ & $\mathrm{~F}$ & 27.6 & CD19+ & 11250000 & 240000 & c & AEG,MD & 941177 & 31596 & 2636 & 6664 & 1330 & 13308 & 1496 & 2727 & 208 & 52 & 2155 & 1020 & 0 \\
\hline $\mathrm{HC}_{-} 35$ & $\mathrm{~F}$ & 28.7 & PBMCs & 8700000 & 1044000 & $\mathrm{E}$ & AEG,MD & 1824932 & 176403 & 17952 & 66414 & 4320 & 48242 & 11813 & 8105 & 1447 & 249 & 11565 & 6271 & 25 \\
\hline HC_36 & $\mathrm{F}$ & 29.7 & PBMCs & 8100000 & 972000 & $\mathrm{E}$ & AEG,MD & 1103351 & 45312 & 8848 & 15726 & 817 & 10931 & 2324 & 1406 & 233 & 10 & 3726 & 1291 & 0 \\
\hline HC_37 & M & 29.9 & PBMCs & 12000000 & 1440000 & $E$ & AEG,MD & 1909727 & 338646 & 44381 & 139814 & 7439 & 91713 & 11746 & 23501 & 1585 & 425 & 8537 & 9479 & 26 \\
\hline HC_3 $38^{-}$ & $\mathrm{F}$ & 30.7 & PBMCs & 12750000 & 1530000 & E & $\mathrm{AEG}, \mathrm{MD}$ & 1877484 & 366879 & 106835 & 148305 & 5245 & 22404 & 13883 & 27944 & 3806 & 323 & 24438 & 13686 & 10 \\
\hline HC_39 & M & 30.9 & PBMCs & 12600000 & 1512000 & $\mathrm{E}$ & AEG,MD & 640010 & 80488 & 8850 & 21591 & 1356 & 14618 & 3007 & 11972 & 658 & 5 & 8369 & 10062 & 0 \\
\hline HC_40 & M & 33.3 & CD19+ & 31800000 & 680000 & c & Mix I & 437659 & 55698 & 10944 & 30331 & 1559 & 6777 & 2617 & 1390 & 993 & 55 & 811 & 220 & 1 \\
\hline HC_41 & $\mathrm{F}$ & 33.7 & PBMCs & 69000000 & 1380000 & $\mathrm{E}$ & AEG,MD & 1786984 & 132252 & 69315 & 31741 & 8289 & 9100 & 4499 & 2946 & 595 & 52 & 4578 & 1134 & 3 \\
\hline HC_42 & $\mathrm{F}$ & 33.8 & CD19+ & 100000000 & 3360000 & c & AEG,MD & 1032835 & 195330 & 28072 & 121411 & 2521 & 23779 & 6294 & 3445 & 1021 & 139 & 4069 & 4566 & 13 \\
\hline $\mathrm{HC}_{-} 43$ & $\mathrm{~F}$ & 34.0 & PBMCs & 3000000 & 123000 & c & $\mathrm{AEG}, \mathrm{MD}$ & 1598313 & 97235 & 42852 & 38597 & 2734 & 5965 & 2844 & 1067 & 336 & 49 & 2136 & 636 & 19 \\
\hline HC_44 & M & 35.3 & PBMCs & 15000000 & 1800000 & $\mathrm{E}$ & Mix I & 4584690 & 303597 & 43302 & 86951 & 11700 & 117932 & 19339 & 7425 & 3176 & 94 & 7750 & 5926 & 2 \\
\hline HC_45 & M & 35.7 & PBMCs & 6480000 & 777600 & $\mathrm{E}$ & $\mathrm{AEG}, \mathrm{MD}$ & 943459 & 124374 & 24273 & 36725 & 12340 & 38562 & 3062 & 4235 & 701 & 37 & 3080 & 1359 & 0 \\
\hline HC_46 & $\mathrm{F}$ & 36.3 & PBMCs & 21600000 & 1300000 & $E$ & AEG,MD & 1833493 & 187445 & 53829 & 67615 & 5050 & 20383 & 7927 & 16069 & 982 & 224 & 10156 & 5193 & 17 \\
\hline HC_47 & M & 39.3 & PBMCs & 51000000 & 6120000 & $\mathrm{E}$ & Mix I & 454024 & 47055 & 5645 & 17603 & 1553 & 14413 & 3212 & 1697 & 701 & 17 & 1230 & 968 & 16 \\
\hline HC_48 & M & 41.4 & PBMCs & 16500000 & 1980000 & $\mathrm{E}$ & AEG,MD & 903117 & 110233 & 32876 & 32955 & 10024 & 20751 & 2524 & 6928 & 640 & 5 & 2326 & 1204 & 0 \\
\hline HC_49 & M & 42.6 & PBMCs & 5700000 & 684000 & $\mathrm{E}$ & AEG,MD & 878951 & 86541 & 26443 & 42918 & 1667 & 7504 & 2296 & 2206 & 360 & 49 & 2121 & 947 & 30 \\
\hline HC_50 & M & 42.7 & PBMCs & 10000000 & 1200000 & $\mathrm{E}$ & AEG,MD & 1668134 & 69380 & 6353 & 31589 & 611 & 8976 & 3172 & 3722 & 1135 & 78 & 9926 & 3805 & 13 \\
\hline HC_51 & $\mathrm{F}$ & 45.3 & PBMCs & 8400000 & 1008000 & $\mathrm{E}$ & AEG,MD & 1445580 & 168554 & 16932 & 37464 & 6789 & 43558 & 9925 & 27511 & 1502 & 143 & 16832 & 7879 & 19 \\
\hline HC_52 & $\mathrm{F}$ & 45.4 & PBMCs & 13200000 & 1580000 & $\mathrm{E}$ & AEG,MD & 1694914 & 261324 & 80587 & 85933 & 15323 & 37856 & 9798 & 8977 & 4003 & 316 & 11782 & 6690 & 59 \\
\hline HC_53 & $\mathrm{F}$ & 50.7 & PBMCs & 9600000 & 1152000 & $\mathrm{E}$ & $\mathrm{AEG}, \mathrm{MD}$ & 1970119 & 116853 & 15337 & 26192 & 8018 & 32846 & 15563 & 4098 & 1241 & 47 & 8088 & 5414 & 9 \\
\hline
\end{tabular}


Supplementary table 2

\begin{tabular}{|c|c|}
\hline Primer & \\
\hline CHA $\_70 x$ & GTGACTGGAGTTCAGACGTGTGCTCTTCCGATCTNNNNTNNNNTNNNNGAYGACCACGTTCCCATC*T \\
\hline CHM_70x & GTGACTGGAGTTCAGACGTGTGCTCTTCCGATCTNNNNTNNNNTNNNNTCGTATCCGACGGGGAATT*C \\
\hline CHD $70 x$ & GTGACTGGAGTTCAGACGTGTGCTCTTCCGATCTNNNNTNNNNTNNNNGGGCTGTTATCCTTTGGGT*G \\
\hline CHE $70 x$ & GTGACTGGAGTTCAGACGTGTGCTCTTCCGATCTNNNNTNNNNTNNNNAGAGTCACGGAGGTGGCATT \\
\hline CHG $70 x$ & GTGACTGGAGTTCAGACGTGTGCTCTTCCGATCTNNNNTNNNNTNNNNAGTAGTCCTTGACCAGGCA*G \\
\hline IGHV1 50x & ACACTCTTTCCCTACACGACGCTCTTCCGATCTGGCCTCAGTGAAGGTCTCCTGCAA*G \\
\hline IGHV2 $50 x$ & ACACTCTTTCCCTACACGACGCTCTTCCGATCTGTCTGGTCCTACGCTGGTGAAACC ${ }^{*} \mathrm{C}$ \\
\hline IGHV3_50x & ACACTCTTTCCCTACACGACGCTCTTCCGATCTCTGGGGGGTCCCTGAGACTCTCCT*G \\
\hline IGHV4_50x & ACACTCTTTCCCTACACGACGCTCTTCCGATCTCTTCGGAGACCCTGTCCCTCACCT*G \\
\hline IGHV5 50x & АCACTCTTTCCCTACACGACGCTCTTCCGATCTCGGGGAGTCTCTGAACATCTCCTG* ${ }^{*}$ \\
\hline IGHV6 50x & ACACTCTTTTCCCTACACGACGCTCTTCCGATCTTCGCAGACCCTCTCACTCACCTGT*G \\
\hline PCR1 rev & CTAGCCTTCTCGTGTGCAGACTTGAGGTCAGTG \\
\hline AD50x_i1 & AATGATACGGCGACCACCGAGATCTACACTATAG \\
\hline $\mathrm{x}$ i2 & AATGATACGGCGACCACCGAGATCTACACATAGAGGCACACTCTTTCCCTACACGACGC \\
\hline AD50x i3 & AATGATACGGCGACCACCGAGATCTACACCCTATCCTACACTCTTTCCCTACACGACGCTCTTCCGATCT \\
\hline AD50x i4 & AATGATACGGCGACCACCGAGATCTACACGGCTCTGAACACTCTTTCCCTACACGACGCTCTTCCGATC ${ }^{\star} T$ \\
\hline AD50x i5 & AATGATACGGCGACCACCGAGATCTACACAGGCGAAGACACTCTTTCCCTACACGACGCTCTTCCGATC ${ }^{*} T$ \\
\hline AD50x i6 & AATGATACGGCGACCACCGAGATCTACACTAATCTTAACACTCTTTCCCTACACGACGCTCTTCCGATC* ${ }^{\star} T$ \\
\hline AD50x i7 & AATGATACGGCGACCACCGAGATCTACACCAGGACGTACACTCTTTCCCTACACGACGCTCTTCCGATC ${ }^{\star} T$ \\
\hline $\mathrm{x}$ & AATGATACGGCGACCACCGAGATCTACACGTACTGACACACTCTTTCCCTACACGACGCTCTTCCGATC* ${ }^{*}$ \\
\hline AD70x i1 & CAAGCAGAAGACGGCATACGAGATCGAGTAATGTGACTGGAGTTCAGACGTGTGCTCTTCCGAT*C \\
\hline AD70x i2 & CAAGCAGAAGACGGCATACGAGATTCTCCGGAGTGACTGGAGTTCAGACGTGTGCTCTTCCGAT*C \\
\hline AD70x i3 & AGAAGACGGCATACGAGATAATGAGCGGTGACTGGAGTTCAGACGTGTGCTCTTCCGAT*C \\
\hline AD70x i 4 & GTGACTGGAGTTCAGACGTGTGCTCTTCCGAT*C \\
\hline AD70x i5 & CAAGCAGAAGACGGCATACGAGATTTCTGAATGTGACTGGAGTTCAGACGTGTGCTCTTCCGAT*C \\
\hline AD70x i6 & CAAGCAGAAGACGGCATACGAGATACGAATTCGTGACTGGAGTTCAGACGTGTGCTCTTCCGAT*C \\
\hline AD70x i7 & AGACGTGTGCTCTTCCGAT*C \\
\hline AD70x i8 & CAAGCAGAAGACGGCATACGAGATGCGCATTAGTGACTGGAGTTCAGACGTGTGCTCTTCCGAT*C \\
\hline AD70x i9 & CAAGCAGAAGACGGCATACGAGATCATAGCCGGTGACTGGAGTTCAGACGTGTGCTCTTCCGAT ${ }^{\star} C$ \\
\hline AD70x i10 & CAAGCAGAAGACGGCATACGAGATTTCGCGGAGTGACTGGAGTTCAGACGTGTGCTCTTCCGAT*C \\
\hline x i11 & AGAAGACGGCATACG \\
\hline AD70x i12 & ATCTATCGCTGTGACTGGAGTTCAGACGTGTGCTCTTCCGAT*C \\
\hline
\end{tabular}

Reverse Transcription

Primers_mix

Primers

Concent

\begin{tabular}{|c|c|c|}
\hline MD mix & AEG mix
\end{tabular}

Primers

(uM)
\begin{tabular}{c|c} 
MD mix & AEG mix \\
\hline
\end{tabular} \begin{tabular}{r|r} 
CHM_70x & Ch \\
\hline 0.625 & \\
\end{tabular}

CHD_70x

CHA_70x

CHE_70x

\begin{tabular}{|r|r|}
\hline 0.25 & CHG_70x \\
\hline
\end{tabular}

CHM_70x

$70 x$

CHD_70x

Mix I

$70 \mathrm{x}$

CHE_70x

25
CHG_70x

Total

2.5

PCR2

Primer

\begin{tabular}{|c|c|c}
\hline IGHV1_50x & IGHV2_50x & IGHV3_50x \\
\multicolumn{3}{|c}{1.25}
\end{tabular}

\begin{tabular}{l|l|l|l}
\hline IGHV4_50x & IGHV5_50x & IGHV6_50x & PCR1_rev
\end{tabular}

Trotal

\begin{tabular}{|l|l|l|ll|}
\hline Primer & AD70x & AD50x & Total & \\
\hline Concentration (UM) & & 1.25 & 1.25 & \\
\hline
\end{tabular}

